\title{
LA FIGURA DEL VINO EN LA OBRA DE WILLIAM SHAKESPEARE
}

\author{
María Asunción Barreras Gómez \\ Universidad de La Rioja
}

A Carmelo Cunchillos, mi maestro y amigo

RESUMEN: Este artículo estudia el significado del vino en la estructura de las obras de Shakespeare. Se analizará cómo subraya momentos climáticos, relajados o es básico en el desarrollo de la intriga y el desenlaza del drama. También se estudiará la variedad de temas con los que se puede relacionar el vino desde las clases sociales, a celebraciones y traición. Destaca el personaje de Fastaff, como veremos, en relación con el líquido elemento. También se estudiarán las palabras más utilizadas por Shakespeare para denominar al vino y se apreciará que estos términos están relacionados con España, como sherris y canaries.

ABSTRACT: This paper studies the meaning of wine in the dramatic structure of Shakespeare's plays. We will analyse how wine underlines climatic or relaxed moments and how it is basic for the plot or intrigue of the play. We will study all the topics related with wine, such as social classes, celebrations or treachery. Finally, we will also analyse Shakespeare's most used words for wine in his dramatic production. Therefore, we will appreciate how they are related to Spain, such as sherris and canaries.

PALABRAS CLAVE: Vino, estructura, temas, palabras.

KEYWORDS: Wine, structure, topics, words.

* La autora pertenece al Centro de Investigación en Lenguas Aplicadas (CILAP) y al Grupo de Investigación Cultura y Vino de la Universidad de La Rioja. Este artículo entronca con la línea de investigación "El vino en la Literatura y la Cultura inglesa". 


\section{Introducción}

Existen análisis específicos sobre la obra de Shakespeare, como el de Pérez Gallego (1989) o Pan Sánchez (1994) que se basan en los personajes aragoneses y navarros, respectivamente, como el de Maley (2003) que analiza las implicaciones de la historia en la comprensión de la obra de Shakespeare y, en general, la literatura renacentista inglesa o el de Cohen (1993) con su lectura marxista sobre el mercader de Venecia. También destacan unos pocos, como Pérez Casaux (1986), Mainardi y Berta (1991) y Muro Munilla (2006), que se centran en el vino en la historia de la literatura y, por tanto, hacen mención del mismo en la obra de Shakespeare.

El siguiente estudio también es específico y versará sobre la utilización del vino en su obra dramática. Como se comprobará, se utilizarán todas las citas donde se menciona el vino en la obra dramática de Shakespeare con el fin de exponer los ejemplos concretos en su totalidad, acudiendo, así, a las fuentes originales. Se utilizará una metodología ecléctica que nos permitirá agrupar las citas por temas y poder explicarlos y nos ayudará a valorar los términos que utiliza el autor para referirse al líquido elemento.

Aunque son pocas, hay algunas obras dramáticas de Shakespeare donde no existe ninguna alusión al vino. Así sucede en Cymbeline, Love's Labour's Lost. Measure for Measure, The Two Gentlemen of Verona, Winter's tale, Titus Andronicus, King John, Richard II y la tercera parte de Henry VI. Sin embargo, existe un gran número de alusiones al vino en el resto de sus obras teatrales. Es un eco de la costumbre social de su consumo en la época.

Será precisamente la utilización del vino en la obra dramática de Shakespeare el objeto de este estudio. Se han rastreado todas las citas referentes al vino en esta obra dramática. Se han agrupado por temas y en los diversos apartados de este trabajo se explicará la figura del vino de una forma completa debido a la ejemplificación tan detallada que se ha hecho. Se estudiarán dichas citas y se mostrará la simbología del vino en momentos y estados diferentes de los personajes y del drama en cuestión. En ellos se comentará su uso, significado, términos utilizados, etc. Así entenderemos mejor su papel en la obra del autor.

\section{El vino en la obra dramática de William Shakespeare}

Desde sus orígenes el vino ha sido un elemento muy importante en la cultura. Siempre ha aparecido en la literatura, música y plástica. Como veremos, en la obra de Shakespeare contextualiza o subraya las escenas. Se aprecian sus efectos 
negativos, para poder traicionar y engañar, y sus efectos positivos para poder festejar y celebrar. Los siguientes temas son los que aparecen asociados al vino en la obra dramática del autor.

\subsection{El vino: pócima de curación}

Hoy en día es reconocido por el FIVIN (Fundación para la Investigación del Vino y Nutrición) el valor del vino en la dieta mediterránea, si se consume de manera moderada. El vino tiene potasio, sodio, hierro y alcohol. Pero, además, contiene taninos que tienen un papel cardioprotector, antioxidante y astringente que favorecen la regeneración de la piel, así como contiene resveratrol que previene los tumores. Los griegos ya conocían algunos aspectos medicinales del vino (Fernández Martín-Granizo 1999: 57). De hecho, Homero en La Iliada nos cuenta cómo Podalirio, hijo del dios de la medicina, cura unas heridas con vino a Filocteres, héroe de la mitología griega y famosos por su arco y flechas (García y Gracía 2001: 148).

En el contexto cultural de Shakespeare ya existían tratados en los que se destacaba el uso del vino para sanar. Así, por ejemplo, en el Compendio de la humana salud del siglo XV se aconseja su utilización contra el cólera. También aparece en Tratados de la peste y en el Tratado de las apostemas se recomienda su uso externo para sanar (Martín 1998: 28). Destaca en el periodo del renacimiento los tratadistas franceses que lo recomiendan para mejorar la salud (Fernández Martín-Granizo 1999: 71). Un eco de esta utilización del vino se refleja en la obra dramática de Shakespeare.

En ocasiones el vino aparece en Shakespeare como un brebaje que pueda devolver la vida y la salud. Como destaca Fernández Martín-Garnizo (1999: 83), “el vino tiene una acción antigangregante planquetaria, un efecto vasodilatador y una acción antiinflamatoria". Así en The Tempest encontramos las siguientes citas, donde se destaca su uso sanador:

\footnotetext{
Stephano- He's in his fit now; and does not talk after the wisest. He shall taste of my bottle: if he have never drunk wine afore, it will go near to remove his fit: if I can recover him, and keep him tame, I will not take too much for him: he shall pay for him that hath him, and that soundly...

Stephano- Four legs, and two voices; a most delicate monster! His forward voices now is to speak well of his friends; his backward voice is to utter
} 
foul speeches, and to detract. If all the wine in my bottle will recover him, I will help his ague: Come, -Amen! I will pour some in thy other mouth ${ }^{1}$. (Shakespeare 1993: 9; énfasis añadido)

Más adelante en la misma obra, The Tempest, aparece un tonel de vino como la forma de salvación del hundimiento de un barco. Parece ser una metáfora visual de esta característica del vino.

Stephano- How did'st thou 'scape? How cam's thou hither? swear by this bottle, how thou cam'st hither. I escaped upon a butt of sack, which the sailors heaved over-board, by this bottle! which I made of the bark of a tree, with mine own hands, since I was cast a-shore ${ }^{2}$. (Shakespeare 1993: 9; énfasis añadido)

Destaca de este ejemplo el hecho de que se tenga que jurar, no por Dios, sino por una botella, se sobreentiende de vino. Es como si el efecto sanador del vino diera la vida y ese aspecto adquiriera tal efecto divino que se admitiera jurar por una botella y no por Dios o sobre una Biblia.

Hay otro ejemplo donde se aprecia que el vino ha sido utilizado para curar heridas y se apela al vino para conseguir ese objetivo. De hecho, se utilizaba como desinfectante para poder limpiar las heridas (Bujanda 2001: 135) Así en Anthony and Cleopatra:

\author{
Mark Anthony- Do so, we'll speak to them; and to-night \\ I'll force \\ The wine peep through their scars. -Come on \\ My queen ${ }^{3}$; (Shakespeare 1993: 659; énfasis añadido)
}

1. Stephano- Está ahora en pleno acceso y no hace sino delirar. Le daré un trago. Y si no ha probado antes vino alguno, seguro que éste le cura el ataque. Si en verdad se restablece y lo amanso, nunca será bastante lo que pida por él, pues quienquiera que lo compre habrá de pagarlo, y con creces...

Stephano- ¡Cuatro patas y dos voces...! ¡Oh, monstruo delicadísimo! La voz de delante le sirve para alabar a sus amigos y por la trasera dice guarradas y difamaciones. Aunque todo el vino de la botella necesitara para curarlo, he de hacerle bajar esa fiebre. ¡Venga!... ¡Amén! Ahora por la boca trasera... (Shakespeare 1994: 238-239).

2. Stephano- ¿Cómo te escapaste? ¿Cómo llegaste hasta aquí? Júrame por esta botella... ¿Cómo llegaste? Yo me salvé a bordo de un tonel de Jerez que los marineros habían arrojado al mar. Lo juro por esa botella que hice, apenas llegué a tierra, con la corteza de un árbol. (Shakespeare 1994: 243).

3. Antonio- Hacedlo así; les hablaré, y esta noche obligaré a que les salga vino por las cicatrices. Vamos allá, mi reina. (Shakespeare 1983: 147). 
Más adelante en la misma obra, Anthony and Cleopatra, Marco Antonio, que se siente morir, bebe vino para conseguir fuerzas y poder hablar, algo que también destaca Mainardi y Berta (1991: 117).

Mark Anthony- I am dying, Egypt, dying;

Give me some wine, and let me speak a little ${ }^{4}$.

(Shakespeare 1993: 665; énfasis añadido)

Hay que recordar que en Roma el vino tenía consideración por médicos y naturalistas, como Plinio el viejo y Galeno (Fernández Martín-Granizo 1999: 70). De hecho, el primero consideraba que el vino da fuerza a la sangre, ayuda al estomago y evita las preocupaciones (Bujanda 2001: 136). Es precisamente para tomar fuerzas por lo que Marco Antonio lo pide.

En general y como se ha mostrado, cuando el vino enseña sus cualidades curativas en Shakespeare, el autor lo hace de forma realista y contribuye a crear el contexto histórico que muestra en sus obras.

\subsection{El vino, amistad, alegría y fiesta}

Desde siempre se han unido estos cuatro componentes. El autor griego Alceo relacionaba el vino con "beber junto a los amigos". Como destaca Oroz (1985: 38), beber vino manifiesta una relación comunitaria de amistad. Además, también el vino se utiliza para celebrar una ocasión o un encuentro, siempre es motivo de una reunión social. Forma parte de la manera en la que se lleva a cabo esa celebración. Es un elemento que muestra la alegría (recordemos a los dioses del vino griego y romano, Dionisios y Baco), la bienvenida o la paz del momento. Esta costumbre social también la muestra Shakespeare en su obra.

De esta manera, el vino sirve para dar la bienvenida, como sucede en esta cita de la segunda parte de Henry $I V$.

\footnotetext{
Fastaff- Welcome, ancient Pistol. Here, Pistol,

I charge you with a cup of sack: do you discharge

upon mine hostess 5 .

(Shakespeare 1993: 375; énfasis añadido)
}

4. Antonio- Me muero, reina de Egipto, me muero. Dadme vino, y dejadme hablar un poco. (Shakespeare 1983: 168).

5. Falstaff- Bien venido séais, abanderado Pistol, os cargo con una copa de vino de Canarias; descargaos vos sobre la posadera. (Shakespeare $2000 \mathrm{~d}$ : 749). 
En el siguiente ejemplo, que pertenece también a la segunda parte de Henry $I V$, se aprecia cómo el vino está unido a un momento relajado, cálido y amable.

Pistol- Then, feed and be fat, my fair Calipolis:

Come, give's some sack.

Si fortuna me tormenta, sperato me contenta.-

Fear we broadsides? no, let the fiend give fire:

Give me some sack; -and, sweetheart, lie thou

there [Laying down his sword] ${ }^{6}$.

(Shakespeare 1993: 375; énfasis añadido)

En la siguiente cita de la segunda parte de Henry $I V$, vemos cómo se unen los efectos secundarios del vino junto con la alegría que hay en una celebración.

Shallow- A good varlet, a good varlet, a very good

varlet, Sir John. - By the mass, I have drunk

too much sack at supper: ...

[singing]

Shallow- Give master Bardolph, some wine, Davy

Davy- Sweet Sir, sit. ...

Shallow- Be merry, master Bardolph...7 (Shakespeare 1993: 389; énfasis añadido)

En el siguiente ejemplo, que también perteneciente a la segunda parte de Henry IV, vemos cómo el vino se une a la alegría, la fiesta y la celebración.

Shallow- Give master Bardolph some wine, Davy.

...

Davy- Your worship? - I'll be with you

straight [To Bard] -A cup of wine, sir?

Silence- $A$ cup of wine,

that's brisk and fine,

And drink unto the leman mine;

And a merry heart lives long-a;

Falstaff- Well said, master Silence.

6. Pistol- Entonces, come y engorda, mi bella calípolis. Vamos, dadnos un poco de vino de Canarias.

Si fortuna me tormenta, sperato me contenta. (Shakespeare $2000 \mathrm{~d}: 752$ ).

¿Tememos a las anadadas? No, que el demonio haga fuego. Dadme vino canario, y tú, mi bien amada, reposa aquí. (Deja a un lado la espada). (Shakespeare 2000 d: 478).

7. Shallow- Un buen pícaro, un buen pícaro, un buen pícaro, sir Juan... ¡Por la misa que he bebido demasiado canarias en la cena!...

(cantando).

Shallow- Dad vino a maese Bardolf, Davy.

Davy-Amable señor, sentaos...

Shallow-Alegraos, maese Bardolf... (Shakespeare 2000 d: 808-809). 
Silence- And we shall be merry; -now comes in the sweet of the night ${ }^{8}$. (Shakespeare 1993: 389; énfasis añadido)

En The Life and Death of King Henry the Eighth se cita al vino en la bienvenida que se da a una fiesta, donde todo tiene que ser alegría.

Guilford- Salutes ye all; This night he dedicates

to fair content, and you: none here, he hopes,

in all this noble bevy, has brought with her

one care abroad: he would have all as merry

as first-good company, good wine, good

welcome ${ }^{9}$. (Shakespeare 1993: 525; énfasis añadido)

En Romeo and Juliet, aparece el vino con las mismas connotaciones:

Servant- Now I'll tell you without asking:

My master is the great rich Capulet;

and if you be not of the house of Montagues,

I pray, come and crush a cup of wine.

Rest you merry ${ }^{10}$. (Shakespeare 1993: 767; énfasis añadido)

Es la invitación que hace el criado al principio de la obra a todo aquel que no sea de la casa de los Montesco. El vino forma parte de una fiesta en la que habrá paz, por eso no entran los Montesco, y en la que habrá diversión.

Esta misma estructura se repite en otras obras del autor. La siguiente cita pertenece a Macbeth:

Macbeth- ...Then I'll sit down:_ Give me some wine, fill full:

I drink to the general joy of the whole table ${ }^{11}$,

(Shakespeare 1993: 291; énfasis añadido)

8. Shallow- Dad vino a maese Bardolf, Davy.

Davy- ¿señoría? (A Bardolf) Soy con vos al instante. ¿Un vaso de vino, señor?

Silencio- (canta) Un vaso de vino espumeante y claro

para que beba a la salud de mi amada

y el corazón alegre vive mucho tiempo.

Falstaff- Bien dicho, señor Silencio.

Silencio-Y nosotros estaremos alegres también. Ahora viene el momento gozoso de la noche. (Shakespeare $2000 \mathrm{~d}: 808-809)$.

9. Guilford-Señoras, un saludo y bienvenida general para todas de parte de su eminencia. Esta noche la dedica a vosotras y al sano regocijo. Espero que ninguna de esta noble asamblea traiga consigo un pesar. Quisiera que todas estuvierais tan alegres como cumple a buenas personas que gozan de excelente y buena compañía, buen vino y buen recibimiento... ¡ Oh milord, os habéis retardado! (Shakespeare 2000 d: 965).

10. Criado- Ahora os lo diré, sin que me lo preguntéis: mi amo es el riquísimo Capuleto; y si no sois vos de la casa de los Montesco, os ruego vengáis y vaciéis una copa de vino. ¡Que os divirtáis! (Shakespeare 2004: 34).

11. Macbeth: Me sentaré. Servidme vino: ¡así hasta los bordes! Brindo por la alegría de esta mesa... (Shakespeare 2004: 150). 
Esta es una de las pocas ocasiones de alegría en la mesa del rey Macbeth, aunque el contexto general en el que se produce sea el asesinato del legítimo rey. Pide que se llene el vaso para brindar por ella. Recordemos, además, que en las comidas era muy normal el vino ya desde la Roma clásica, ya que la cena estaba compuesta de tres partes, la gustatio, la cena propiamente dicha y la secunda mensae o postre. En la gustatio se servían entremeses acompañados de "mulsum o vino mezclado con miel, vino de falerno, Marsala o vino griego de resina" (Otero 1996: 346). Esta costumbre de la utilización del vino en las comidas se va heredando hasta llegar a la época de Shakespeare.

Hay otras ocasiones en las que se habla de la bebida como forma de celebrar una situación. Así lo encontramos en Hamlet, Prince of Denmark. En esta cita vemos al rey celebrando con una copa de vino el acierto de la espada de Hamlet.

King- Set the stoups of wine upon that table:-

If Hamlet give the first or second hit,

Or quit in answer of the third exchange,

Let all the battlements their ordnance fire:

The king shall drink to Hamlet's better breath;

And in the cup an union shall he throw,

Richer than that which four successive kings

In Denmark's crown have worn; Give me the cups; ...

Now the king drinks to Hamlet.- Come, begin;-- ${ }^{12}$

(Shakespeare 1993: 817; énfasis añadido)

Un ejemplo similar en el que se brinda por Pericles tiene lugar en Pericles, Prince of Tyre.

Simonides- ...

Here say, we drink this standing-bowl of wine

to him $^{13}$. (Shakespeare 1993: 724; énfasis añadido)

Hay veces que se utiliza al vino como marco que acompaña la fiesta, como colofón de la paz y el bienestar, como sucede en el siguiente ejemplo de Merry Wives of Windsor.

12. Rey- Poned sobre la mesa las jarras de vino. Si Hamlet da el primer golpe o el segundo, o está al quite en el tercer asalto, haré que en las almenas disparen salvas de ordenanza, y el rey beberá por el éxito de Hamlet y ha de introducir en su copa una perla, la más preciosda que en su corona hayan llevado los cuatro últimos reyes de Dinamarca. ¡Las copas!... Beba el rey ahora a la salud de Hamlet. (Shakespeare 1993: 693).

13. Simónides- ...decidle que bebemos a su salud esta copa de vino. (Shakespeare 2000 b: 642). 
Host- Peace, I say; hear mine host of the Garter. Am I politck? Am I subtle?...

I have directed you to

Wrong places: your hearts are mighty, your

Skins are whole, and let burn sack be the issue

-Come, lay their swords to pawn: -Follow

me, lad of peace ${ }^{14}$. (Shakespeare 1993: 44-45; énfasis añadido)

El vino forma parte de la paz y de la celebración que ofrece el hostelero como contraposición al ruido de las espadas. En esa mima obra, Merry Wives of Windsor, encontramos más ejemplos en el que el vino va unido a la fiesta.

Ford- Trust me a good know: I have good cheer

At home; and, I pray you all, go with me...

Slender-... We have appointed

To dine with mistress Anne...

Ford- [aside] I think I shall drink in pipe

Wine first with him. I'll make him dance. Will

you go, gentles? ${ }^{15}$ (Shakespeare 1993: 45; énfasis añadido)

En este ejemplo se aprecia que el vino no puede faltar en una celebración. Además, el vino en un comedia de este tipo, como afirma Mainardi y Berta (1991: 117), "è adeguato al tono comico dell'opera ed è spesso expediente che provoca il riso".

Sin embargo, también se ve que el vino se asocia con la pérdida de voluntad, ya que Ford sabe que, una vez bebido vino, será capaz de hacer bailar a quien quiera.

El vino se une a lo positivo en el contexto del buen comer y como algo que todo el mundo quiere degustar. Así en The first part of King Henry the Sixth encontramos:

Talbot- ... No other satisfaction do I crave,

But only (with your patience) that we may

taste of your wine, and see what cates you have;

14. Hostelero- ¡Basta, digo! Escuchad a vuestro hostelero de la Jarretiera. ¿Soy un político? ¿Soy un hombre sutil?... Os he conducido a diversos lugares para que no pudierais encontraros. Vuestros corazones son intrépidos, vuestras pieles están intactas, y el desenlace debe ser una liberación del jerez. ¡Vamos, dejad esas armas para el prestamista! ¡Seguidme, gentes de paz! (Shakespeare 2000 c: 931-932). pañéis...

15. ¡Excelente reunión, creedme! Hoy tengo buena mesa en casa, y os ruego a todos que me acom-

Slender- Hemos prometido comer con mistress Ana...

Ford- (aparte) Creo que antes beberé yo con él una pipa de vino. Yo le haré danzar. ¿Quereis venir, señores? (Shakespeare 2000 c: 933-934). 
for soldiers' stomachs always serve them well ${ }^{16}$.

(Shakespeare 1993: 423; énfasis añadido)

En la segunda parte de esta misma obra, The Second Part of King Henry the Sixth, hay un claro ejemplo de celebración con el vino con la toma de una ciudad.

Cade- Now is Mortimer lord of this city. And here, sitting upon London-stone, I charge and command, that, of the city's cost, the pissing. Conduit run nothing but claret wine this first year of our reign. And now, henceforward, it shall be treason for any that calls me other than -Lord Mortimer ${ }^{17}$. (Shakespeare 1993: 458; énfasis añadido)

En todas estas citas el vino está unido a una celebración y supone un momento de anticlímax y relajación en la acción de la obra.

\subsection{El vino, inspirador de fuerza y valor}

El alcohol, desde la óptica nutricional, puede ser considerado como fuente de energía o como bebida energética. Un gramo de etanol produce siete kilocalorías (Fernández Martín-Granizo 1999: 44). En los siguientes fragmentos aparece el vino para recabar la energía o valentía que se necesitará en un momento posterior y álgido en la acción de la trama.

Uno de los personajes de Shakespeare más relacionado al vino es Falstaff, como veremos más adelante. En Henry IV, (Shakespeare 1993: 383-384), Falstaff destaca los aspectos positivos que consigue el vino. Entre ellos destaca la agilidad, la ocurrencia y la valentía. Al vino se le atribuye la consecución del coraje, también en otros ejemplos teatrales. Así en Henry $V$ leemos:

Constable-Dieu de battailes! Where have they this

mettle?...

And shall our quick blood, spirited with wine,

16. Talbot- No solicito otra satisfacción que obtener de vos el permiso de dejarnos saborear vuestro vino y de ver qué provisiones tenéis; pues los estómagos de los soldados están siempre dispuestos. (Shakespeare 2000 d: 50).

17. Ahora es Mortimer dueño de esta ciudad, y aquí, sentado sobre el hito de Londres, ordeno y mando que las fuentes durante este primer año de nuestro reinado, no orinen de sus caños más que vino clarete, y eso a expensas de la ciudad. Y desde ahora será un caso de traición el llamarme de otro modo que Lord Mortimer. (Shakespeare 2000 d: 168). 
seem frosty? O, for honour of our land ${ }^{18}$, (Shakespeare 1993: 402; énfasis añadido)

Se une el valor de la sangre al que previamente se haya bebido.

\section{En The Tempest encontramos:}

Trinculo- Thou liest, most ignorant monster; I am in case to justle a constable: Why, thou debosh'd fish thou, was there ever man a coward, that hath drunk so much sack as I to-day? Wilt thou tell a monstruous he, being but half a fish, and half a monster? (Shakespeare 1993: 11; énfasis añadido) ${ }^{19}$

Trínculo entiende que no puede comportarse como un cobarde, porque ha bebido vino. Tiene que ser útil. Por tanto, une su bravura con el vino.

El vino en estos ejemplos suele preceder a momentos de tensión y climax, ya que normalmente el personaje bebe vino para tomar fuerzas y llevar a cabo un hecho importante en la trama de la obra.

\subsection{Vino versus cerveza: un paradigma social}

El vino siempre ha sido esencial en un buen banquete. Así se demuestra en las Notas de cocina, escritas por Leonardo da Vinci en la corte milanesa de Ludovico Sforza o en El banquete de Plutarco (Martín 1998: 9-17). Además, el banquete o la buena mesa siempre se asocia a los dirigentes de la sociedad, a la clase alta, capaz de costearlo. El buen comer es considerado un acto social, por ejemplo, para agasajar a algún convidado. Por otro lado y como destaca Martín (1998: 49), puede llegar a reflejar "las diferencias sociales, la situación económica o la educación de los comensales" $"$.

18. Condestable- ¡Dios de las batallas! ¿Dónde han adquirido ellos esa valentía? ... ¿Y nuestra sangre tan viva, animada con el vino, va a aparecer helada? ¡Oh!, por el honor de nuestro suelo (Shakespeare $2000 \mathrm{~d}: 870)$.

19. Trínculo- ¡Mientes, ignorante monstruo! Estoy en condiciones de derribar a un alguacil. Escucha, pez de la depravación, ¿puede ser cobarde un hombre que ha bebido el Jerez que yo he bebido hoy? ¡Calla tú, mentiroso mostrenco, que no eres más que pez por delante y monstruo por detrás! (Shakespeare 1994: 275).

20. No en vano, en el refranero español podemos encontrar el siguiente: "en la mesa y en el juego se demuestra el caballero". 
Este hecho ha sido subrayado desde la antigüedad. Por ejemplo, los súbditos del faraón tomaban cerveza, mientras que el faraón, vino. Virgilio apuntaba que la cerveza era "propia de los bárbaros, indignos del dios Baco" (Fernández Martín-Granizo 1999: 22-24), es decir del dios relacionado con el vino.

Esta misma característica elitista se muestra en Shakespeare. En general, la utilización del vino de esta manera contextualiza las escenas e, incluso, puede subrayarse ese carácter social en una escena cómica o dramática.

Hay momentos de las obras de Shakespeare en los que el vino se bebe en grandes banquetes de personajes importantes.

Esta situación se ve reflejada en las obras que tratan argumentos y personajes de épocas anteriores. Así, por ejemplo, en la introducción a Anthony and Cleopatra, se apunta "se nos dan frecuentes imágenes basadas en la comida y bebida, que abundan los placeres que proporcionan exquisitos manjares y afrodisíacos licores" (Shakespeare 1983: XVIII). De nuevo, estas imágenes se refieren a las relacionadas con las clases altas.

Domitius Enobarbus: Bring in the banquet quickly;

Wine enough,

Cleopatra's health to drink ${ }^{21}$. (Shakespeare 1993: 643; énfasis añadido)

Pompey-Sit, -and some wine. - A health to

Lepidus...

Pompey- Forbear me till anon.-

This wine for Lepidus ${ }^{22}$. (Shakespeare 1993: 652; énfasis añadido)

Mark Anthony- Some wine, within there, and our viands:-

Fortune knows,

We scorn her most, when she offers blows ${ }^{23}$. (Shakespeare 1993: 658; énfasis añadido)

Son citas donde vemos a los grandes celebrar algo, vitorear a alguien o olvidar alguna pena con vino.

21. Enorbarbo- Traed acá de prisa el banquete, con mucho vino, para beber a la salud de Cleopatra. (Shakespeare 1983: 83).

22. Pompeyo- Sentaos y tomad vino: un brindis por Lépido...

Pompeyo- Espera hasta dentro de un momento. (Susurros al oído) Este vino para Lépido.

(Shakespeare 1983: 118).

23. Antonio- Poned vino ahí, y nuestras viandas. La Fortuna sabe que la desprecio más cuanto más me golpea. (Shakespeare 1983: 140). 


\section{Otra cita similar procede de The Life and Death of Julies Caesar.}

Caesar- Good fiends, go in, and taste some wine with me;

And we, like friends, will straightway go together ${ }^{24}$. (Shakespeare 1993: 630; énfasis añadido)

Brutus- Lucius, a bowl of wine ${ }^{25}$. (Shakespeare 1993: 637; énfasis añadido)

De nuevo, el vino aparece relacionado con la clase alta, en estos casos con el emperador César y Bruto, su hijo.

También encontramos otros ejemplos, como en Twelfth Night; una obra que se caracteriza por ser una comedia de errores y de confusión de identidades (Kermode 2001: 68).

Sir Toby Belch- Thou art a scholar; let us therefore eat and drink. -Marian, I say! -a stoop of wine! ${ }^{26}$ (Shakespeare 1993: 61; énfasis añadido)

Sir Toby Belch- Thou'rt i'the right. -Go, sir, rub your chain with crums: -A stoop of wine, Maria! ${ }^{27}$ (Shakespeare 1993: 62; énfasis añadido)

Sir Toby Belch- Come, come; I'll go burn some sack, 'tis too late to go to bed now: come, knight; come, knight ${ }^{28}$. (Shakespeare 1993: 63; énfasis añadido)

La primera cita refleja a Sir Toby dirigiéndose a Sir Andrew, ambos de la clase alta, sobre acostarse tarde, levantarse pronto o tener la jarra vacía. La segunda muestra a Sir Toby hablando con un payaso y con Malvolio, un mayordomo. Finalmente, la tercera vuelve a reflejar una parte de otra conversación entre Sir Andrew y Sir Toby, ambos de clase alta. Cabe destacar que la afición de Sir Toby por el vino ha sido una característica que se ha destacado como un aspecto común

24. César- Buenos amigos, entremos dentro, y tomad vino conmigo; y luego nos iremos derechos juntos, como amigos. (Shakespeare 1981: 129).

25. Bruto- Lucio, una copa de vino. (Shakespeare 1981: 157).

26. Sir Toby- ¡Cuánta sabiduría! Bebamos, pues y comamos. ¡Marian! ¡Eh, Marian! Una jarra de vino. (Shakespeare 1997: 179).

27. Sir Toby- ¡Teneis toda la razón!... ¡Largo de aquí! (A Malvolio). ¡Id y fregaos la cadena con migas de pan! ¡María, traed una jarra de buen vino! (Shakespeare 1997: 197).

28. Sir Toby- Venga, vamos... flamearemos un buen vaso de jerez, que ya es tarde para irse a la cama ahora... Ea, mi caballero, venga, buen caballero mío. (Shakespeare 1997: 209). 
entre los personajes de Sir Toby y Falstaff, en Henry IV y Merry Wives from Windsor (Therle Lawrence 1969: 174).

En Timon of Athens encontramos otro caso en el que el vino se vuelve a unir con la clase alta, ya que el noble Lúculo pide a uno de sus criados que le traiga vino.

Lucullus- One of Lord Timon's men? a

gift, I warrant...

Fill me some wine.

...

Re-enter servant with wine.

Servant- Please your lordship, here is the wine $e^{29}$.

(Shakespeare 1993: 580; énfasis añadido)

En otro momento de la misma obra, Timon of Athens, observamos que Apemanto expresamente une beber vino con el buen vivir de las clases altas y así dice:

Apemantus- This is in thee a nature but affected;

a poor unmanly melancholy, sprung

from change of fortune. Why this spade? this

place?

this slavelike habit? and these looks of care?

thy flatterers yet wear silk, drink wine, lie soft;

hug their diseas'd perfumes, and have forgot

that ever Timon was $^{30}$. (Shakespeare 1993: 587; énfasis añadido)

En el siguiente ejemplo de Much Ado about Nothing apreciamos cómo Leonato, gobernardor de Messina, por tanto, perteneciente a la clase social alta, ofrece vino como parte de la amabilidad unida a su clase social.

Leonato- Drink some wine ere you go; fare you

well ${ }^{31}$. (Shakespeare 1993: 110; énfasis añadido)

Además, podemos observar que en la época de Shakespeare las clases altas bebían vino, mientras que las bajas bebían cerveza en el siguiente ejemplo. La costumbre social de unir el vino a las clases altas y la cerveza a las clases bajas

29. Lúculo-¿Uno de los hombres del señor Timón? Apuesto que es un regalo... Traedme vino... (Vuelve el criado con el vino).

Criado- Con licencia de vuestra señoría, aquí está el vino. (Shakespeare 2000 b: 551-552).

30. Apemanto- Esta disposición no es en ti más que el resultado de una naturaleza infectada; una pobre melancolía sin virilidad, que ha surgido del cambio de fortuna. ¿por qué esa azada, esa estancia, ese traje que es caso el de un esclavo, y esas miradas adustas? Tus aduladores continúan llevando la seda, bebiendo vino, durmiendo en buenos lechos, acariciando a sus queridas de perfumes perniciosos y han olvidado que haya existido nunca Timón. (Shakespeare 2000 b: 581).

31. Leonato- Bebed un trago de vino antes de partir y pasadlo bien. (Shakespeare $2000 \mathrm{c:}$ 145). 
era conocida en la época y Shakespeare la deja patenta en su obra Taming of the Shrew. En esta obra un criado es objeto de una burla, haciéndole pasar por pertenecer a la clase alta. Se le dice que es un noble señor, aunque todo el mundo sabe que es un criado y está siendo objeto de una broma.

Lord- That done, conduct him to the drunkard's chamber, and call him- madam, do him obeisance,

Tell him from me (as he will win my love),

He bear himself with homourable action,

Such as he hath observ'd in noble ladies

Unto their lords, by them accomplished:

Such duty to the drunkard let him do,...

I long to hear him call the drunkard husband;

And how my men will stay themselves from laughter,

When they do homage to this simple peasant. (Shakespeare 1993: 221)

...

Sly- For God's sake, a pot of small ale.

1 Serv.- Will't please your lordship drink a cup of sack?

$\cdots$

Sly-I am Christophero Sly; call not me honour,

nor lordship: I never drank sack in my

life; and if you give me any conserves, give me

conserves of beef. Ne'er ask me what raiment

I'll wear: for I have no more doublets than

backs, no more sockings than legs, nor no more

shoes than feet; nay, sometimes, more feet than

shoes, or such shoes as my toes look through

the overleather.

Sly- What, would you make me mad? Am not I Christopher Sly, old Sly's son of Burtonheath ... Ask Marian Hacket, the fat ale-wife of Wincot...

if she know me not: if she say I am not fourteen pence on

the score for sheer ale,...

Here's -

$\ldots$

Sly- Am I a lord? And have I such a lady? ...

And once again, a pot o'the smallest ale.

$\cdots$

Enter the page, as a Lady, with attendants.

Page- How fares my noble lord?

Sly- Marry, I fare well; for here is cheer enough.

Where is my wife? ${ }^{32}$ (Shakespeare 1993: 222; énfasis añadido)

32. Lord- ... una vez hecho esto, condúcelo a la cámara del borracho, llámale "señora", y préstale obediencia. Dile de mi parte que, si aprecia mi afecto, se comporte de manera honorable, tal como ha 
En esta cita se pueden apreciar diversos aspectos. En primer lugar, la indefensión en la que queda una persona tras los efectos del alcohol, que en una comedia tiene rasgos divertidos, como en esta broma, y que en las tragedias llevará a terribles conclusiones, como veremos más adelante. Por otro lado, vemos cómo se une el vino a la copa y al cristal, mientras que la cerveza se une a una vasija de cerámica. Por tanto, vemos la diferencia social entre los recipientes que contienen un líquido u otro; el primero, más caro y elegante y el segundo, más barato y tosco. De hecho, el vidrio siempre se ha utilizado como envase del vino desde épocas muy antiguas, recordemos la época de la Roma y Grecia clásicas (Moragón 1994: 531).

Finalmente, vemos cómo un criado no ha bebido vino en su vida, mientras que es lo que normalmente bebe el amo, y cómo la cerveza está más unida a la taberna, donde la mesonera aparece como la esposa de la cerveza. Se da un juego irónico en el que se parodia estos rasgos sociales; siendo la víctima de esta ironía, Sly, ya que se muestra extrañeza y se mofa de que un sirviente beba vino como su señor.

Otro ejemplo similar en el que vino se contrapone a la cerveza es el siguiente de la segunda parte de Henry IV.

observado que lo hacen las damas nobles hacia sus señores. Que haga esto ante el borracho con toda cortesía,... (Shakespeare 2004: 475) me muero de ganas de oír cómo llama marido al borracho y de ver a mis criados reprimir la risa cuando rinden homenaje a este simple campesino...

SLY (despertándose)- Por amor de Dios, una jara de cerveza ligera.

Sirviente 1.- ¿Le apetecería a vuestra señoría beber una copa de jerez?

SLY- Soy Christopher Sly, no me llaméis merced ni señoría; no he bebido jerez en mi vida y si me dais conservas, que sean de buey nunca me preguntéis los trajes que voy a llevar, porque no tengo más jubones que espaldas, ni más medias que piernas, ni más zapatos que pies y, a veces, más pies que zapatos, o zapatos tales que se ven los dedos. (Shakespeare 2004: 476).

...

SLY- ¿Qué, queréis volverme loco? ¿No soy yo Christopher Sly, el hijo primogénito de la familia Burton...? Preguntad a Marian Hacket, la gorda mesonera de Winkcot ... si no me conoce, si no tengo una deuda con ella de catorce peniques por cerveza pura... (Un sirviente le trae un jarro de cerveza.) ¡Qué! No estoy loco: aquí está. (Bebe). (Shakespeare 2004: 477).

SLY- ¡Soy yo un lord? ¿Y tengo una dama tal? ... y una vez más un jarro de vuestra cerveza más ligera.

Entra el paje como una dama con sirvientas; una da a Sly una jarra de cerveza.

Paje- ¿Cómo le va a mi noble lord?

Sly- Contento, me va bien, porque aquí hay suficiente comida. ¿Dónde está mi esposa? (Bebe). (Shakespeare 2004: 478). 
Doll Tearsheet- Away, you cut-purse rascal! you filthy bung, away! by this wine, I'll thrust my knife in your mouldy chaps, an you play the sancy cuttle with me. Away, you bottle-ale rascal! you basket-hilt stale juggler, you! -Since when, I pray you, sir? -What, with two points on your shoulder? much! ${ }^{33}$ (Shakespeare 1993: 375; énfasis añadido)

No se aprecia bien en la traducción, porque el traductor no se centra en la palabra ale, que significa cerveza. Sin embargo, en el texto inglés se aprecia cómo Shakespeare une bottle-ale, botella de cerveza, a bribón de clase baja. De nuevo, se ve que la cerveza se une a la clase baja.

Por otro lado, también se destaca las diferencias sociales en la época de Shakespeare (Frye 1986: 16). Estilísticamente el autor utiliza tanto la prosa como el verso en sus obras. Sin embargo, la prosa es utilizada por personajes de clase social baja o en momentos de baja intensidad, mientras que el verso es utilizado por los de clase social alta o en momentos de intensidad alta, como aparece en la introducción de As you like it (Shakespeare 1985: XIX). En este caso, un momento de intensidad, no se reconoce en su situación de señor, y, por eso, el sirviente habla en verso. En esta cita se puede apreciar, además, la dicotomía entre las dos bebidas que representan a las dos únicas clases sociales del momento, la alta y la baja. De esta forma, le ofrecen a Sly a cup of sack, es decir una copa de vino.

Sack: Any of various light, dry, strong wines from Spain and the Canary Islands imported to England in the 16th and 17 th century. (The American Heritage Dictionary)

En este ejemplo vemos que el vino y, en concreto, el vino de España es el que se asocia a las capas altas de la sociedad. Mientras que "ale", es decir, la cerveza es una bebida de la clase baja y sirve para demostrar su condición social por lo que pide cerveza.

Queremos resaltar los términos sack y malmsey ${ }^{34}$ por los que se conocía los vinos de Canarias en Gran Bretaña (Lorenzo-Cáceres 1941: 29). Sin embargo, en la obra de Shakespeare aparece señalados con la palabra sack. Hay veces que el

33. Doll Tearsheet- ¡Atrás, bribón cortabolsas; atrás, sucio bitoque! Por este vino, que os envaino mi cuchillo en vuestras podridas mandíbulas como hagáis el soldadote grosero conmigo! ¡Atrás, canalla, borracho! ¡Atrás, desmirriado juglar de guarnición de espada! ¿Desde cuándo esas maneras, que me quereis decir, señor? ¡Luz de Dios, por dos agujetas que lleva en el hombro! ¡Vaya! (Shakespeare 2000 d: 750).

34. Se traduce al castellano como malvasía. Era del particular uso de los cosecheros y valía el doble en el mercado (Lorenzo-Cáceres 1941: 30). 
autor utiliza dicho término, sack, para jugar con él y podemos encontrar casos en los que, por ejemplo, Falstaff hable de vino con la palabra sack y otros personajes utilicen esa misma palabra con el significado de saco. Así:

Prince Henry: How now, wool-sack, what mutter you $?^{35}$ (Shakespeare 1993: 351; énfasis añadido)

Vemos un juego de palabras con el significado de saco y vino para referirise a Falstaff, un personaje especialmente unido al consumo de este vino, como también destaca en su estudio sobre el vino en la literatura Mainardi y Berta (1991). Este personaje aparece en Merry Wives of Windsor y Henry IV. Falstaff pertenece a la clase baja, pero en la obra histórica está cerca del príncipe Hal. Esto le hace conocer aspectos relacionados con la clase alta, como es el caso del vino español. Es interesante destacar este personaje en este estudio, porque se le relaciona constantemente con el vino.

Falstaff proviene del miles gloriosus clásico y de Vice de las Morality Plays inglesas. MacLeish y Unwin (2000: 134) aseguran que es heredero de "figuras como el Dionisios de la antigua Grecia o el señor del Caos de los entremeses navideños de Inglaterra"

Falstaff se muestra como un mujeriego, mentiroso, vago, ladronzuelo, cobarde y juerguista. Su tratamiento en la obra histórica es más serio que el que se da en la comedia. Una obra, ésta última, escrita a petición de la reina Elisabeth I, que quería ver a Falstaff enamorado (Nevo 1980: 143). Así, en Merry Wives of Windsor vemos cómo Falstaff le escribe una carta de amor a una mujer casada con la que quiere mantener una relación y una de las características positivas que destaca es su aprecio por el vino español. En el segundo ejemplo también lo vemos demostrando su aprecio por ese mismo vino. Finalmente, en el tercer ejemplo de la misma obra aparece una descripción de lo que Fastaff es:

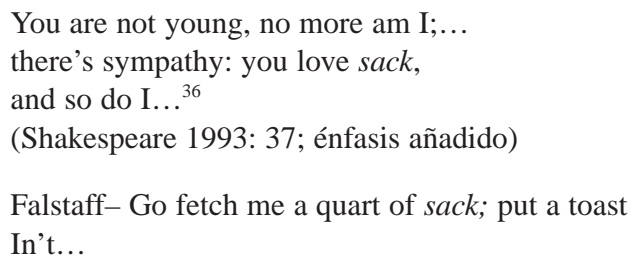

35. Príncipe Enrique- ¿Qué decís, saco de lana, qué murmuráis? (Shakespeare 2000 d: 641).

36. Ya no sois joven, yo tampoco lo soy;... Pues más simpatía, entonces. A vos os gusta el jerez, a mí también. (Shakespeare 2000 d: 1104). 
Re-enter Bardolph, with wine...

Falstaff-Come, let me pour in some sack to the

Thames water; for my belly's as cold, as if I had Swallowed snow-balls for pills to cool the reins... Falstaff-Take Away these chalices: Go brew me A pottle of sack finely ${ }^{37}$.

(Shakespeare 1993: 48; énfasis añadido)

Evans- And given to fornications, and to taVerns, and sack, and wine, and metheglins, and To drinkings, and swearings and starings, pribbles and prabbles? ${ }^{38}$ (Shakespeare 1993: 55; énfasis añadido)

Sin embargo, es en la primera parte de Henry IV donde aparece Falstaff mejor representado como el personaje de vicio antes aludido. Normalmente el borracho ha sido siempre descrito de forma negativa. En el Levítico o en el Eclesiástico de la Biblia se critican los abusos de vino, es uno de los siete pecados capitales medievales (Lucero et al: 39 y 159) y también es censurado en el Espéculo de los legos (Martín 1998: 26). Esto mismo sucederá con Falstaff en Henry IV.

Así es cómo piensa el príncipe que su padre hablaría de Falstaff y lo que Falstaff piensa que el joven príncipe diría de él, al hablar con su padre.

Prince Henry- Why dost thou converse

With that trunk of humours...

That huge bombard of sack, that stuffed cloak-

Bag of guts...

That reverended vice...

Wherein is he good, but to taste sack

And drink it?...

Falstaff- But to say, I know more harm in him

Than in myself...

If sack and sugar be a fault,, God help the

Wicked! $!^{39}$ (Shakespeare 1993: 354; énfasis añadido)

37. Falstaff- Ve a traerme una pinta de Canarias; colócate una tostada encima.

Vuelve a entrar Bardolf con el vino de Canarias.

Falstaff- Llévate esos dos cálices y ve a prepararme un pote fino de jerez.

(Shakespeare $2000 \mathrm{~d}: 1123$ ).

38. Evans- Entregado a las fornicaciones, a las tabernas, al canarias, al viento, al hidromiel, a los licores fuertes, jugador escandaloso y camorrista. (Shakespeare $2000 \mathrm{~d}: 1139$ ).

39. Principe Henry- ¿Por qué conversas con ese baúl de bufandas... esa enorme bombarda de Canarias, portamantas de tripas? ¿Para qué sirve sino para saborear el Canarias y tragarlo?

Falstaff- Pero decir que conozco en él más mal que en mí mismo sería decir más de lo que sé... Si el canarias con azucar es un defecto ¡Que Dios perdone al miserable! (Shakespeare 2000 d: 652-653). 
En esta conversación se aprecia la pésima influencia que Falstaff, a quien llama hombre gordo y hombre tonel, ejerce sobre el joven príncipe y cómo su padre le insta a no prestarle atención. A pesar de esto, el propio Falstaff justifica los pecados de Falstaff.

Hay más ejemplos de Shakespeare, donde aparece el mismo personaje, cuyo objetivo es mostrar la apetencia de Falstaff por el vino español, sack, así como por mostrar lo negativo que es el abusar del mismo. De hecho, el vino y la embriaguez es "tópico obligado de la literatura moral que expone sobre los vicios y los pecados mortales" (Lucero et al. 1990: 18). El eco de la morality play inglesa se apreciará en el personaje de Falstaff.

En la primera parte de Henry $I V$, leemos la siguiente cita:

Prince Henry- Thou art so fat-witted, with drinking

Of old sack, and unbuttoning thee alter supper,

And sleeping upon benches alter noon,...

What the devil hast thou

To do with the time of the day? Unless hours

Were cups of sack, and minutes capons ${ }^{40}$.

(Shakespeare 1993: 344; énfasis añadido)

Armstrong y Atkin (1998: 72) comentan que esta cita muestra una gran facilidad de lenguaje, ya que se utiliza un vocabulario muy simple, con pocas palabras y compuestas de dos o tres sílabas. Su control sintáctico es perfecto y transforma un crudo ataque en una retórica sofisticada. Añaden que Hal utiliza una lista de palabras relacionadas con la bebida y la taberna, como "drinking, old sack, cups of sack, capons, bawds, leaping-houses" y acuña palabras propias, como "fat-witted." Añaden que esta última palabra sirve para caracterizar a Falstaff, que lleva a la estupefacción y es mentalmente torpe. Pero, además, en esta cita el personaje está lleno de alegría y buen humor, con lo que permite asociar la gordura con el buen humor. Pérez Casaux (1986: 31) destaca este aspecto, ya que describe a Falstaff como un buen vividor y un "compañero inapreciable de las inocentes juergas y aventuras amorosas del príncipe Enrique".

Otro ejemplo en el que se le caracteriza a Falstaff como amante del vino en la primera parte de Henry $I V$ es el siguiente:

40. Príncipe- Te has embrutecido de tal modo, a fuerza de beber vino añejo de Canarias, de desabrocharte después de cenar y de dormir la siesta en los bancos... ¿Qué diablos tienes tú que ver con el momento del día? A menos que las horas sean como las copas del vino de Canarias, los minutos capones (Shakespeare $2000 \mathrm{~d}$ : 609-610). 
Falstaff- Bardolph, get thee before to Conventry:

fill me a bottle of sack; our soldiers shall march

through; we'll to Sutton-Colfield to-night ${ }^{41}$.

(Shakespeare 1993: 260; énfasis añadido)

En este ejemplo de la primera parte de Henry IV, Falstaff une el vino con el mal vivir y, por eso, quiere adelgazar, dejar el vino y ser decente.

Falstaff- I'll follow, as they say, for reward. He that rewards me, God reward him! If I do grow great; I'll grow less; for I'llpurge, and leave sack, and live cleanly, as a nobleman should do ${ }^{42}$. (Shakespeare 1993:365; énfasis añadido)

Otro ejemplo menor de Falstaff relacionado con el vino es el siguiente de la segunda parte de Henry IV.

Falstaff- Some sack, Francis ${ }^{43}$. (Shakespeare 1993: 376; énfasis añadido)

Esta obra histórica no es una comedia, como sucede en Merry Wives of Winsdor, y el retrato que se da de Falstaff es más crudo. Además, en esta obra Falstaff es el contrapunto del protagonista, el futuro Henry $\mathrm{V}$ y que todavía es príncipe. Se trata de un príncipe que se acerca a Falstaff en su juventud, pero que pasa a representar todo lo contrario de lo que es Falstaff ${ }^{44}$ cuando se aproxima a su faceta de rey. En este sentido, Kermode (2005: 103) y Hyland (1996: 178) destacan que el rechazo que sufre Falstaff cuando el joven príncipe se convierte en rey es necesario para que se convierta en un monarca virtuoso.

En el siguiente ejemplo de la primera parte de Henry IV se ve cómo el príncipe Enrique se distancia de Falstaff y sus vicios. En un momento anterior el príncipe le reprocha no haber luchado y vengado a sus muertos. Por otro lado y como se ve en esta cita, el príncipe también le reprocha que se haya dedicado a beber vino, en vez de haberse dedicado a la batalla, y, por esa razón, le devuelve la botella, sin beber, y se va. Es uno de los momentos en los que se aprecia que el príncipe madura y se aleja del vicio, de Falstaff, para prepararse y llegar a ser un buen rey.

41. Falstaff- Bardolf, adelántate a Coventry y lléname una botella de vino de canarias; nuestros soldados atrevesarán la ciudad. Debemos estar esta noche en Sutton Co'fil. (Shakespeare 2000 d: 680).

42. Falstaff- Quiero seguir, como me dicen, para obtener recompensa. ¡El que me recompense a mí, que Dios le recompense! Si llego a ser más grande, estaré menos grueso, pues me purgaré y dejaré el canarias y viviré decentamente, como conviene a un noble. (Shakespeare 2000 d: 702).

43. Falstaff- ¡Un poco de vino canario, Francisco! (Shakespeare 2000 d: 756).

44. De hecho, en la escena segunda del primer acto se le llama a Flastaff, Sir John Sack and Sugar. Un mote que recoge su debilidad por el vino español. 
Prince Henry- Give it me; is it the case?

Falstaff- Ay, Hal: 'tis hot; there's that will sack a city.

[The prince draws out a bottle of sack]

Prince Henry- What, is't a time to jest and dally now?

[Throws it at him, and exit] ${ }^{45}$ (Shakespeare 1993: 364; énfasis añadido)

Los vicios de Falstaff en las obras donde aparece, pero especialmente en Henry IV, permiten destacar mejor las aspectos positivos del príncipe Hal, su contrapunto, especialmente en la segunda obra citada. Falstaff es un personaje que se caracteriza por ser vago, avaricioso, lujurioso, ladrón, mentiroso, glotón y bebedor, especialmente de "sack" (Nevo 1980: 147). Es un personaje que influye en el modo de vida del príncipe en sus inicios, pero éste acabará apartando, como lo hace con la botella, para llegar a ser un buen gobernante y, como culminación de su proceso de maduración y de aprendizaje, para llegar a ser un buen rey. Además, es interesante apreciar en esta cita el juego de palabras con la palabra sack, al significar saquear y vino de Canarias.

Otra cita donde se aprecia la filosofía de Falstaff hacia el vino y cómo éste considera que el príncipe Henry es superior es la siguiente. Pertenece a la segunda parte de Henry IV. En este ejemplo Falstaff une el tener hijas (visión machista de la sociedad por considerarlo negativo ante la posibilidad de tener varones), el pescado y bebidas flojas a la sangre fría, a no reír, a ser tonto y cobarde por no beber. Luego describe cuál es el proceso del vino dentro del cuerpo humano: sube al cerebro, acaba con todas las ideas absurdas y da expresión a ideas ingeniosas en la lengua. Cabe destacar que todas estas características y procesos ya se habían explicado en la obra medieval, Virtudes del vino (Martín 1998: 27). El personaje también destaca los aspectos positivos que consigue el vino con el hombre. De acuerdo con Falstaff, el que bebe vino es ágil, ligero, ocurrente y valiente. Todas estas características conseguidas con el vino se ejemplifican con el príncipe Enrique, ya que éste es valiente por herencia de su padre y porque bebe vino de Jerez.

Falstaff- I would you had but the wit: t'were better than your dukedom. -Good faith, this same young sober-blooded boy doth not love me; nor a man cannot make him laugh; -but

45. Príncipe Enrique- Dámela, ¿Cómo es que está en su funda?

Falstaff- $\mathrm{Si}, \mathrm{Hal}$; está caliente, está caliente. Hay aquí con que saquear una ciudad. [El príncipe saca de la funda una botella de canarias]

Príncipe Enrique- ¡Cómo! ¿Es este el momento de bromear y chancear? [Le devuelve la botella y sale] (Shakespeare $2000 \mathrm{~d}: 697$ ). 
that's no marvel, he drinks no wine. There's never any of these demure boys come to any proof: for thin drink doth so over-cool their blood, and making many fish-meals, that they fall into a kind of male green-sickness; and then, when they marry, they get wenches; they are generally fools and cowards; -which some of us should be too, but for inflammation: A good sherris sack hath a two-fold operation in it. It ascends me into the brain; dries me there all the foolish, and dull, and crudy vapours which environ it: makes it apprehensive, quick, forgetive, full of mimble, fiery, and delectable shapes; which delivered o'er to the voice (the tongue), which is the birth, becomes excellent eit. The second property of your excellent sherris is, -the warming of the blood; which, before cold and settled, left the liver white and pale, which is the badge of pusillanimity and cowardice: but the sherris warms it, and makes it course from the inwards to the parts extreme. It illumineth the face: which, as a beacon, gives warning to all the rest of this little kingdom, man, to arm: and then the vital commoners, and inland petty spirits, muster me all to their capatain, the heart: who, great, and puffed up with this retinue, doth any deed of courage; and this valour comes of sherris: So that skill in the weappon is nothing, without sack; for that sets it a work; and learning a mere hoard of gold kept by a eil; till sack commences it, and sets it in act and use. Hereof comes it, the Prince Henry is valiant: for the cold blood he did naturally inherit of his father, he hath, like lean, steril, and bare land, manured, husbauded, and tilted, with excellent endeavour of drinking good, and good store fertile sherris; that he is become very hot and valiant. If I had a thousands sons, the first human principle I would teach them, should be, -to forswear thin potations, and addict themselves to $s a c k^{46}$. (Shakespeare 1993: 383-384; énfasis añadido)

46. Falstaff- Os desearía solamente inteligencia. eso valdría más que vuestro ducado. Hablando de buena fe, este joven de sangre fría no me quiere; nadie puede hacerle reír; pero no es extraño; no bebe 
En esta cita el personaje destaca las virtudes del vino. Además, une la figura del príncipe de Gales como "laborioso y noble y bebe vino" (Pérez Casaux 1986: 33). Posiblemente no haya mejor alabanza al vino y, en concreto, al vino español en toda la literatura inglesa, como afirma Pérez Casaux (1986).

Destaca el hecho de que lo denomine también sherry, que es definido como:

An amber-colored fortified Spanish Wine ranking from very dry to sweet. [Alteration of obs sherris (taken as pl), alter Xeres, Jerez, Spain] (The American Heritage Dictionary)

Por tanto, en la cita anterior se especifica que el vino del que se habla es de color ámbar y sabor fuerte, resaltando el hecho de que procede de la región de Jerez, en España. Se utiliza una palabra que deriva de una ciudad española, como cuando se alude también al vino como canaries.

La cita anterior resalta los efectos físicos que causa el vino, lo que permite relacionarla con el siguiente ejemplo de la segunda parte de Henry IV, la señora Quickly comenta cuáles son los efectos físicos que produce el vino como las mejillas sonrosadas. Además, también habla de la facilidad con que penetra, sin apenas enterarse.

Hostess (Mrs Quickly) I'faith, sweet heart, methinks now you are in an excellent good temperality: your pul-

sidge beats as extraordinarily as heart would

vino. Jamás ninguno de estos mozos tan moderados llegan a nada; porque su bebida floja les enfría más a la sangre, y el hacer muchas comidas de pesacado les hace caer en una especie de opilación masculina. Cuando se casan, engnedran hijas. Son generalmente tontos y cobardes, lo que seríamos también algunos de nosotros si no fuese por el calentamiento. Un buen jerez produce un doble efecto: primero, se me sube al interior de cerebro, me seca allí todos los necios, torpes y malolientes vapores que lo envuelven; lo hace abierto, ágil, inventivo, pleno e concepciones ligeras, ardientes y deleitosas formas; todo lo cual, comunicad a la voz, la lengua, que le da expresión, produce excelentes ocurrencias. La segunda propiedad de vuestro excelente jerez es la de calentar la sangre, que estando antes fría y calmosa dejaba el hígado blanco y pálido, lo que es signo de pusilanimidad y cobardía; pero el vino de jerez la calienta y la hace correr del centro a las partes extremas. Ilumina el rostro, que, como un faro, ordena armarse a todo el resto de este pequeño reino, el hambre: y entonces toda la burguesía de los espíritus vitales y los pequeños espíritus interiores se reúnen alrededor de su capitán, el corazón, quien, potente y ufano de su ejército realiza cualquier acto que sea de valor; y este valor viene del jerez. De aquí se sigue que la destreza en las armas no es nada sin el vino de Jerez; porque es él quien la pone en acción, y el saber no es más que un simple montón de oro guardado por un diablo, hasta que el jerez se apodera de él y le da vida y empleo. De ahí viene que el príncipe Enrique sea valiente; porque esa sangre fría que ha heredado, naturalmente, de su padre, la tiene, como se hace con una tierra floja, estéril y yerma, laborada, cultivada y sembrada por el excelente trabajo del buen beber y por el buen abono del fértil jerez. De suerte que ha llegado a ser muy ardoroso y muy valiente. Si mil hijos tuviera, el primer principio humano que les enseñaría sería abjurar de toda bebida insípida y dedicarse al jerez. (Shakespeare 2000 d: 788-789). 
desire; and your colour, I warrant you, is as red as any rose; But I'faith, you have drunk too much canaries; and that's a marvellous searching wine, and it perfumes the blood ere one can say, -what's this? How do you now ${ }^{47}$ (Shakespeare 1993: 374; énfasis añadido)

Cabe destacar la utilización del término canaries para referirse al vino. Por un lado, resalta la importancia del vino canario que ha sido clave en las islas desde siempre (Béthencourt 2003: 7). Por otro lado, significa que este vino español tenía entidad propia en la cultura británica de la época. En este sentido, es importante el estudio de Béthencourt (2003), que se centra en el comercio de vinos entre Canarias e Inglaterra durante los años 1650 y 1800. Justifica su importancia en Gran Bretaña, ya que esta monografía se centra en el estudio del comercio y la transacción de vinos entre los dos lugares que, con sus altibajos, era fluida.

Existen otras obras de Shakespeare donde se encuentran reflejos de la forma de utilizar el vino. Así, por ejemplo, en King Lear, aparece la siguiente cita:

Edgar- A serving-man, proud in heart and mind;

... that slept in the

contriving of lust, and waked to do it: Wine

loved I deeply; dice clearly; and in woman,

out-paramoured the Turk: False of heart... ${ }^{48}$

(Shakespeare 1993: 751; énfasis añadido)

Se trata de una alusión al vino unido a la vida disoluta y relajada del personaje.

En esta sección se ha apreciado cómo el vino y los recipientes que lo contienen pertenecen a la clase alta, mientras que la cerveza y sus continentes pertenecen a la clase baja. Destaca el personaje de Falstaff, perteneciente a la clase baja y amante del vino, conocedor del mismo por su contacto con la clase alta al ser amigo del príncipe Hal.

47. Mrs Quickly- Verdaderamente, corazón querido, me parece que os halláis ahora en un excelente buen "timple"; vuestro "pulso" late tan extraordinariamente como el corazón puede apetecerlo, y en cuanto a vuestras mejillas, os garantizo que están tan encarnadas como cualquier rosa, dicho sea con sinceridad, ¡eh! Pero, por mi fe, habéis bebido demasiado canarias; es un vino maravillosamente penetrante y que perfuma la sangre antes que se pueda decir: ¿Qué es esto?” "¿Cómo os sentís ahora? (Shakespeare 2000 d: 747).

48. Edgar- Un siervo orgullosos de corazón y espíritu... Acariciaba en sueños la lujuria para satisfacerla al despertar. Apasionadamente amaba el vino y los dados y superaba al gran turco en mujeres. De corazón falso... (Shakespeare 1995: 175). 


\subsection{El vino, bebida para olvidar}

El alcohol que tiene el vino puede provocar la relajación hasta el punto de perder la consciencia. Ayuda a dejar de tener en la memoria lo que se tenía o debía tener. De esta forma ha sido utilizado en ocasiones por los personajes de Shakespeare, como veremos a continuación, y que responde a una demanda real que se le ha hecho al vino desde siempre.

Así la inconsciencia que ofrece el vino se utiliza como forma de olvidar tristezas. Por ejemplo, en The Merchant of Venice:

Gratiano- Let me play the fool:

With mirth and laughter let old wrinkles come; and let my liver rather heat with wine, Than my heart cool with mortifying groans ${ }^{49}$.

(Shakespeare 1993: 158; énfasis añadido)

Gratiano es consciente de utilizar el vino para olvidar los pesares de su corazón. Sabe también que se reirán de él en su estado, pero prefiere olvidar para no estar triste y pesaroso.

También existen otros ejemplos relacionados con Falstaff $^{50}$ en la primera parte de Henry IV. Así dice:

Falstaff- Go, hang thyself in thy own heir-appa rent garters! If I be ta'en, I'll peach for this.

And I have not ballads made on you all, and sung

To filthy tunes, let a cup of sack be my poison:

When a jest is so forward, and Afto. Too, -I

Hate it ${ }^{51}$. (Shakespeare 1993: 349; énfasis añadido)

Falstaff se encuentra desairado porque no tiene caballo y, además, ve que el príncipe Hal no le quiere ayudar. Por tanto, decide tomarse un vaso de vino para

49. Gratiano- Permitidme que yo haga el de bufón y que me salgan las arrugas entre las alegrías y risas, y que el vino caliente mi hígado antes de que mi corazón se enfríe con mortificantes quejidos. (Shakespeare 2004: 555).

50. En el libro Malvasía y Falstaff. Los vinos de Canarias Lorenzo-Cáceres (1941) cita diversos ejemplos en los que aparece Falstaff relacionado con el vino de Canarias, sack. Sin embargo, no hace un análisis comentado de los mismos o una clasificación.

51. Falstaff- Anda pues, y que te ahorquen con tus jarretas de presunto heredero. Si me cogen, os acusaré. Si no mando que se hagan baladas acerca de vosotros y se os canten aires cochinos, que se me dé un vaso de vino dulce como veneno. Cuando una broma va tan lejos ¿y además a pie!..., la odio. (Shakespeare $2000 \mathrm{~d}: 630$ ). 
encarar mejor la situación. Sabe que para él es negativo, por lo que lo denomina veneno, sin embargo, le es necesario para encarar su situación.

La siguiente cita hace alusión a un momento de la misma obra, primera parte de Henry IV, en la que el vino le ayuda a Falstaff a relajarse ante una situación adversa:

Falstaff- A plague of all cowards, I say and a Vengeance too! Marry, and amen!- Give me $a$ Cup of sack, boy. - Ere I lead this life long, I'll

Sew neither-stocks, and menú them, and foot Them too. A plague of all cowards!- Give me A cup of sack, rogue. - Is there no virtud exant? (He drinks) $)^{52}$. (Shakespeare 1993: 351; énfasis añadido)

Ha observado que los que le rodean no son valientes y decide beber para sentirse más relajado para mostrarse bravo.

Un poco más adelante tiene unas palabras con el príncipe Henry y Falstaff comenta:

Falstaff: You are straight enough in the shoulders, you

Care not who sees your back: Call you that

Backing of your friends? A plague upon Duch

Backing! Give me them that will face me-

Give me $a$ cup of sack; - I am a rogue, if I

Drunk to-day ${ }^{53}$. (Shakespeare 1993: 351; énfasis añadido)

Falstaff percibe que el príncipe no le tiene ya en mucha consideración, por eso pide una copa de vino, aún sabiendo que no lo debería hacer. De nuevo, necesita el vino para aceptar su nueva situación de menosprecio por parte del príncipe y se reconoce como bellaco por no poder dejar de beber.

Se puede apreciar otro ejemplo en la obra Richard III:

Clarence: Where art thou, keeper? Give me $a$ cup of wine.

52. Falstaff- ¡Mala peste le caiga a todos los cobardes y la venganza de añadidura! ¡De veras! ¡Amen!..., digo yo... Dame un vaso de canarias, muchacho... Antes de llevar esta vida largo tiempo, preferiría coser calcetines y remendarlos y ponerles plantas también. ¡Mala peste a todos los cobardes! Dame un vaso de canarias, pillastre. ¿No hay virtud en la actualidad? (Bebe) (Shakespeare $2000 \mathrm{~d}$ : 640).

53. Falstaff-Tenéis las espaldas bastante anchas y no os preocupáis de los que os puedan ver detrás. ¿Llamáis a eso respaldar a vuestros amigos? ¡Maldito sea tal respaldo! Dame gentes que miren a la cara... Dame un vaso de canarias... Soy un bellaco,, si bebí hoy. (Shakespeare 2000 d: 641). 
First Murderer: You shall have wine enough, my lord, anon ${ }^{54}$.

(Shakespeare 1993: 498; énfasis añadido)

En esta cita vemos que Clarence está en la prisión y quiere tomar vino para sobrellevar su situación de condena. No sabe que está hablando con uno de sus asesinos y éste le dice que tendrá suficiente de inmediato, ya que su fin está próximo.

En la cita de The Life and Death of Julies Caesar vemos que Bruto y Casio beben vino para superar una pena de amores.

Enter Lucius, with wine and Tapers.

Brutus- Speak no more of her. -Give a bowl

of wine:-

In this I bury all unkindness, Cassius. [Drinks]

Cassius- My heart is thirsty for that noble pledge:-

Fill, Lucius, till the wine o'erswell the cup;

I cannot drink too much of Brutus' love. [Drinks] $]^{55}$

(Shakespeare 1993: 637; énfasis añadido)

Cuando los personajes son débiles, cuando sus situaciones son demasiado difíciles para sobrellevarlas éstos beben vino con el fin de superar las situaciones y olvidarlas. Estas citas donde aparece el vino son anticlímax de la acción y subrayan las debilidades del momento.

\subsection{El vino, la traición, el engaño y la debilidad}

Como ya queda patente en la figura de Falstaff, el vino puede dar paso a la borrachera. Sin embargo, la borrachera no siempre da lugar a chanzas y a burlas. Hay casos en las tragedias, como ya se ha comentado, en los que se utiliza el vino para emborrachar a un personaje y sacar beneficio de su estado de embriaguez, que es más bien considerado una desgracia. En este caso la utilización del vino responde a la falta que se comete quebrantando la lealtad que se le debe tener a alguien. Se asocia a la falta de verdad en lo que se dice o se hace. El resultado de esta acción consciente y egoísta provoca la debilidad, la carencia de energía en aquel del que se quiere aprovechar.

54. Clarence- ¿Dónde estás, carcelero? ¡Dame una copa de vino!

Asesino prímero- Dentro de un instante tendréis suficiente vino, milord. (Shakespeare 2000 d: 314).

55. Entra el mozo [Lucio], con vino y velas.

Bruto- No hables más de ella. Dame un copa de vino: en ella sepulto toda aspereza, Casio. (Bebe).

Casio- Mi corazón está sediento de este noble brindis. Llena, Lucio, hasta que le vino rebose de la copa: no puedo beber suficiente del cariño de Bruto. (Bebe). (Shakespeare 1981: 157-158). 
Por ejemplo, en Macbeth, al emborrachar a los soldados que guardan al rey Duncan que descansa en el castillo de Macbeth, a éste le resulta sencillo conseguir la corona. Lady Macbeth, y como se verá en otros ejemplo de esta sección, utiliza el vino como droga ${ }^{56}$ para conseguir sus fines.

Lady Macbeth- Was the hope drunk,

Wherein you dress'd yourself? hath it slept

since?

And wakes it now, to look so green and pale

At what it did so freely?... . (Shakespeare 1993: 285) ${ }^{57}$

Lady Macbeth- We fail!

But screw your courage to the sticking place,

And we'll not fail. When Duncan is asleep

(Whereto the rather shall hisday's hard journey

Soundly invite him), his two chamberlains

Will I with wine and wassel so convince,

That memory, the warder of the brain,

Shall be a fume, and the receipt of reason

A limbeck only: When in swinish sleep

Their drenched natures lie, as in a death,

What cannot you and I perfom upon

The unguarded Duncan? What not put upon

His spongy officers; who shall bear the guilt

of our great quell? (Shakespeare 1993: 285; énfasis añadido) ${ }^{58}$

Lady Macbeth- That which hath made them drunk,

hath made me bold:

What hath quench'd them, hath given me fire:

-Hark! -Peace!...

The doors are open; and the surfeited grooms

do mock their charge with snores: I have

drugg' $d$ their possets,

56. La organización Mundial de la Salud (OMS) incluye el alcohol dentro del "grupo de sustancias consideradas como drogas" (Bujanda 2001: 41). Gracias a su componente del alcohol lo utiliza así Lady Macbeth.

57. Lady Macbeth- ¿Era borrachera la esperanza que abrigasteis, y ha dormido desde entonces, y ahora despierta y ofrece verdosa y pálida la faz, temerosa de lo que acogió tan de su albedrío? (Shakespeare 2004 127).

58. Lady Macbeth- ¡Fracasar! Asegurar vuestro valor hasta la tenacidad, y no fracasaremos. Cuando Duncan esté sumido en el sueño, y la dura jornada de hoy le invitará prontamente a dormir, haré que el vino y el brebaje de manzanas y cerveza se apoderen de sus dos chambelanes de modo tal que la memoria, ese guardian del cerebro, será en ellos humo y la razón un alambique. Cuando, abotargados, sus embraigadas naturalezas les tenga yacentes como en la muerte, ¿qué no podremos hacer vos y yo en el indefenso Duncan? ¿Qué no imputaremos en sus chambelanes borrachos, que tendrán que soportar la culpa de nuestro gran asesinato? (Shakespeare 2004: 127-128). 
That death and nature do contend about them

(Shakespeare 1993: 286; énfasis añadido) ${ }^{59}$

En estas citas el vino aparece como un brebaje con el que conseguir fines perversos: emborrachar y dormir a los guardas para matar a su rey y cambiar el orden de las cosas para que un inferior, un general, consiga el trono. El alcohol del vino tiene efectos depresores sobre el sistema nervioso central. Así, la toma de alcohol favorece la facilidad para conciliar el sueño (Bujanda 2001: 45). En el caso de las citas anteriores el vino consigue que duerman los guardianes y es un elemento que lleva a la equivocación (Kermode 2001: 211), ya que son inocentes y parecen culpables ${ }^{60}$. Como destaca Mainardi y Berta (1991: 119), "Anche Lady Machbeth non fa un buon uso del vino". Este juego de reflejos también se destaca en la premonición de las brujas, puesto que le dicen a Macbeth que será rey, pero no le anuncian la forma en la que lo conseguirá.

Es interesante destacar que ha sido el personaje de una mujer la que, junto al vino, ha conseguido estos maléficos objetivos. Por tanto, aparece como una mujer maligna. Así:

La figura de la mujer pecadora con la copa en la mano como emblema de poder, nos acerca a la mujer-Eva, protagonista del amor loco de este mundo combatida por los predicadores, contra cuyas múltiples maneras y mañas se escribieron en la Edad Media tratados, como la Reprobatio Amoris, el tercer libro del De Amore de Andrea Capellanos o Il Corbaccio de Giovanni Boccaccio. (Lucero et al. 1990: 241)

Lady Macbeth utiliza el vino para su propio beneficio. El poder que le otorga el vino para embriagar y hacer perder a los hombres sus sentidos, le permite convertirse en un personaje fuerte, valiente, pero negativo. Se trata de un personaje problemático si tenemos en cuenta el contexto social de la época, ya que ésta debía estar sometida al hombre (Kinney 2001: 167).

Se pueden apreciar otros ejemplos relacionados con el vino, como en Othello, the Moor of Venice. Así "Fingendo allegria e volendo mostrarse amichevole Iago induce a bere Casio" (Mainardi y Berta 1991: 119); de esta manera empezará la tragedia del argumento.

59. Lady Macbeth- Lo que a ellos les ha embriagado a mí me presta osadía: lo que les ha dominado, a mí me anima. ¡Eh, silencio!... Están las puertas abiertas, y los ahítos chambelanes burlan con ronquidos el cumplimiento de sus deberes: les he añadido a su brebaje de leche agria y vino una droga que en estos momentos tiene a sus naturalezas en lucha entre vida y muerte. (Shakespeare 2004: 131).

60. Kermode (2001: 210) se centra en el primero de los ejemplos anteriormente citados para explicar cómo la abstracción "hope" es denominada "drunk". 
Iago- Well, happiness to their sheets! Come, lieutenant, I have a stoop of wine; and here without are a brace of Cyprus gallants, that would fain have a measure to the health, of the black Othello.

Cassio- Not to-night, good Iago; I have very poor and unhappy brains for drinking; I could well wish courtesy would invent some other custom of entertainment.

Iago- O, they our friends; but one cup; I'll drink for you. Cassio-I have drunk but one cup to-night, and that was craftily qualified too, and, behold, what innovation it makes here: I am unfortunate in the infirmity, and dare not task my weakness with any more. (Shakespeare 1993: 827; énfasis añadido) ${ }^{61}$

Iago- If I can fasten but one cup upon him, with that which he hath drunk to-night already, He'll be as full of quarrel and offence as my young mistress' dog... Have I to-night fluster'd with flowing cups, and they watch too. Now, "mongst this flock of drunkards,

Am I to put our Cassio in some action that may offend the isle: (Shakespeare 1993: 827; énfasis añadido) ${ }^{62}$

En estos dos ejemplos apreciamos cómo Iago trama una trampa, emborrachando al noble Cassio y, así, quedarse con su puesto. Como destaca Kermode (2001: 172), Iago ya conoce la debilidad de Casio y se aprovecha. Así Iago se sirve del vino para engañar a Casio y manchar su honor de tal forma que acaba perdiendo el favor de Otelo (Mainardi y Berta 1991: 118).

61. Iago- Bien, ¡que lo disfruten entre las sábanas! Vamos, teniente, tengo una jarra de vino, y aquí fuera ha un par de galanes de Chipre, que de buen gusto harían un brindis a la salud del negro Otelo.

Cassio- No esta noche, buen Yago. Está mi cabeza muy ofuscada y desdichada para la bebida. Bien querría que la cortesía ideara algún otro modo de agasajo.

Iago- Oh, son amigos nuestros. Sólo una copa. Yo en vuestro lugar bebería.

Casio- Tan solo he bebido un acopa esta noche, y más bien aguada. Y fijaos qué turbación ha producido en m cabeza.. Ya soy bastante desdichado en mi flaqueza, y no quisiera aumentarla con una segunda copa. (Shakespeare 2004: 336).

62. Iago- Si logro que se beba una copa más, con la que ya ha bebido esta noche, estará pendenciero y resentido como el perro de mi dama...

También he regalado con vino a tres jóvenes chipriotas de espíritu arrogante y prontos en cuestión de honor, esencia misma de esta isla belicosa, y también están de guardia. Pues bien entre este atajo de borrachos, incitaré a Casio a cometer algún atropello que pueda ofender a la isla. (Shakespeare 2004: 336). 
En otras ocasiones Shakespeare utiliza el vino como un elemento de engaño para conseguir unos fines y muestra a la persona seducida por el vino como alguien débil. Así sucede en la obra Merchant of Venice.
Portia - Therefore, for fear of the worst, I pray
thee, set a deep glass of Rhenish wine on the
contrary casket: for, if the devil be within, and
that temptation without, I know he will choose
it. I will do anything, Nerissa, ere, I will be
married to a spunge. (Shakespeare 1993: 159) ${ }^{63}$

En este ejemplo, Portia utiliza el vino para engañar a su pretendiente y hacerle escoger el cofre equivocado y no casarse con él. Los que utilizan el vino con esos propósitos son personajes manipuladores y saben perfectamente que el vino les hará sucumbir a sus contrincantes y, así, podrán lograr sus objetivos. En este sentido sería una figura similar a Lady Macbeth, ya que es capaz de manipular para conseguir su objetivo. En este sentido, Wilson (1995: 108) comenta: "Portia achieves power over Antonio, Bassanio and even the whole Venice through subverting the patriarchal system of exchange and her place in it as a woman, precisely as an object of exchange". En ese caso concreto Portia es consciente de cómo utilizar el vino y de sus efectos para poder elegir marido libremente, algo novedoso para el momento.

Por otro lado, también destaca en la cita la aparición de los caldos del Rhin, que ya eran conocidos en la época.

En las siguientes citas vemos cómo tiene lugar la trampa que ha diseñado Iago contra Cassio, utilizando el vino para emborracharle, en Othello, the Moor of Venice.

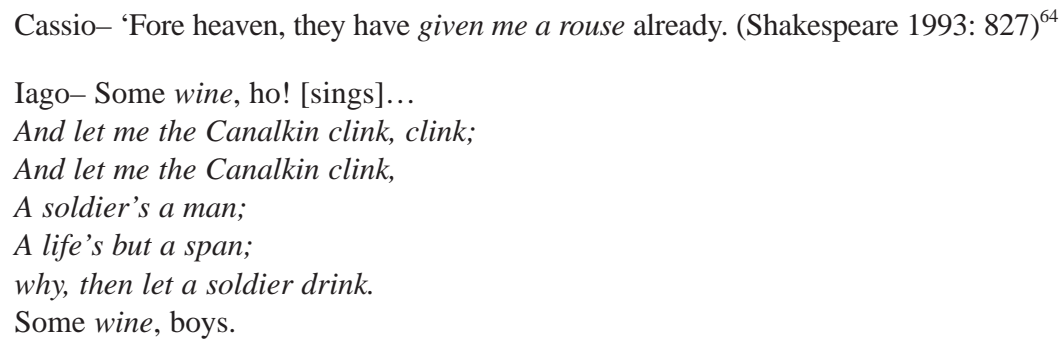

63. Portia- Así pues, por temor a que suceda lo peor, te ruego que coloquen una gran vaso de vino del Rhin sobre el cofrecillo incorrecto, porque, aunque el diablo estuviese dentro y esta tentación fuera, sé lo que escogería... haré cualquier cosa, Nerissa, antes de verme casada con una esponja (Shakespeare 2004: 584).

64. Cassio- Vive Dios, ya me han dado un vaso lleno. (Shakespeare 2004: 337). 
Cassio- 'Fore heaven, an excellent song.

Iago- I learned it in England ... Drink, ho! ...

Cassio- Is your Englishman so expert in his drinking?

Iago- ... Some wine, ho! ...

Cassio- ... Do not think gentlemen,

I am drunk; This is my ancient; -this is my right

hand, and this is my left hand; I am not drunk

now; I can stand well enough, and speak well

enough. (Shakespeare 1993: 828) ${ }^{65}$

Apreciamos cómo Cassio cae en la trampa que le ha tendido Iago y se emborracha, aspecto que también destaca Mainardi y Berta (1991: 119).

Además, como también sucede con Stephano, personaje que bebe y canta, en la escena segunda del acto segundo de The Tempest, se une el vino con la canción.

Iago, como Lady Macbeth con los guardianes, se ha aprovechado de la confianza que Cassio había depositado en él y lo engaña. Le hace beber vino para que se emborrache y entre en disputas con unos chipriotas. En este ejemplo, el vino es utilizado para llevar a Cassio al umbral de los problemas y hacerle quedar mal. Hay un componente de engaño y de aprovechamiento de la borrachera, de la inconsciencia que puede provocar el vino para una mejora personal. Ese engaño que ofrece el vino viene adornado con la amistad que supuestamente le procesa Iago a Cassio y la alegría que también ofrecen las canciones en el momento.

El resultado de este engaño es negativo para Cassio. Ha perdido su honor, la confianza de su superior y su puesto.

Iago- Touch me not so near:

I had rather have this tongue cut from my mouth.

65. Yago- ¡Venga! ¡Que corra el vino!

dejadme sonar mi vaso, chinchin,

dejadme mi vaso sonar.

El soldado es un hombre,

y la vida del hombre un instante

bebe, pues, el soldado.

¡Vino, muchachos!

Cassio- Por el cielo que es una magnífica canción.

Yago- La aprendí en Inglaterra, donde están los más grandes bebedores.

Casssio- ¿Tan consumnado bebedor es el inglés?

Yago- $¡$ Venga, traed vino!

Casio- ... No vayan a pensar, señores, que estoy borracho. Este es mi alferez, mi mano derecha es ésta, y esta otra, mi izquierda, no estoy bebido ahora; puedo estar bien de pie, puedo hablar bien. (Shakespeare 2004: 337-338). 
Than it should do offence to Michael Cassio; ...

Casio- Reputation, reputation! O,

I have lost my reputation! I have lost the im

mortal part, sir, of myself, and what remains

is bestial. -My reputation, Iago, my reputation. (Shakespeare 1993: 829) ${ }^{66}$

Cassio culpa al vino y no a Iago por su comportamiento. Por esta razón, entiende que el vino es algo terrible que puede traer grandes desgracias.

Cassio- I will rather sue to be despised, than to

deceive so good a commander, with so slight,

so drunken, and so indiscreet an officer. Drunk?

and speak parrot? and squabble? swagger?

swear? and discourse fustian with one's own

shadow? -O thou invisible spirit of wine, if

thou hast no name to be known by, let us call

thee -devil. (Shakespeare 1993: 829; énfasis añadido) ${ }^{67}$

Cassio- It hath pleased the devil drunkenness,

to give place to the devil, wrath: one unper-

fectness shows me another, to make me frankly

despise myself. (Shakespeare 1993: 829) ${ }^{68}$

Sin embargo, los dos personajes, Cassio y Iago, no han tenido la misma relación con el vino y por eso, sus visiones hacia el mismo elemento varían. Iago se ha servido del vino y ha sabido utilizarlo para sus maléficos fines. Cassio ha padecido el engaño provocado con el vino y su situación es terrible.

Cassio- I will ask him for my place again; he shall tell me, I am a drunkard!...

Every inordinate cup is unblessed, and the in gredient is a devil.

Iago- Come, come, good wine, is a good fa miliar creature, if it be well used; explain no

66. Yago- No me toqueis tan dentro. Antes arranquen la lengua de mi boca que ofender a Miguel Cassio.

Cassio- ¡Honor!, ¡honor!. ¡He perdido mi honor!. perdido la parte inmortal de mi mismo, y lo que queda es tan solo animal. ¡Mi honor, Yago, mi honor! (Shakespeare 2004: 341-342).

67. Cassio- Antes suplicaria ser despreciado que engañar a tan magnífico comandante con un oficial tan irresponsable, borracho e indiscreto. ¡Emborracharme! ¡Y decir tonterías! ¡Y reñir! ¡Fanfarronear! jjurar! ¡Y hablar ampulosamente con mi propia sombra! Oh, tú, espíritu invisible del vino, ¡si no hay un nombre con el que llamarte, llamémoste, demonio! (Shakespeare 2004: 342).

68. Cassio- Place al demonio de la borrachera dejar su sitio al de la ira. Un vicio me revela otro para que pueda despreciarme con más franqueza. (Shakespeare 2004: 342). 
more against it. And, good lieutenant, I think, you think I love you. (Shakespeare 1993: 829; énfasis añadido) ${ }^{69}$

Un caso similar ocurre en Hamlet, Prince of Denmark, cuando la reina Gertrudis se da cuenta que el vino que acaba de beber está envenenado. No se cita específicamente el vino, pero se sabe que ha sido el vino, porque la bebida que le ha ofrecido el rey ha sido vino. De esta forma, el vino pasa a ser el arma homici$\mathrm{da}^{70}$, en este caso del rey.

King- Gertrude, Do not drink.

Queen-I will, my lord;- I pray you pardon me.

King- It is the poison'd cup; it is too late. [Aside]...

The queen falls $^{71}$. (Shakespeare 817; énfasis añadido)

Queen- No, no, the drink, the drink-Oh,my dear Hamlet!

The drink, the drink: - I am poison'd! [dies] ${ }^{72}$ (Shakespeare: 818; énfasis añadido)

Laertes- It is here Hamlet: Hamlet, thou art slain;

No medicine in the world can do thee good,...

The treacherous instrument is in thy hand...

here I lie,

Never to rise again: Thy mother's poidon'd:

I can no more: The king, the king's to blame ${ }^{73}$. (Shakespeare: 818; énfasis añadido)

Hamlet- Drink off this potion... Follow my mother. [King dies]

Laertes- ...It is a poison temper'd by himself...

Hamlet-Heaven make thee free of it! I follow thee!

I am dead, Horatio...

69. Cassio- Volveré a pedirle mi puesto. Me dirá que soy un borracho... Cada copa de más está maldita y su contenido es un demonio.

Iago- ¡Vamos, vamos! el buen vino es un noble amigo si se usa con prudencia. No digais nada más en contra suya. Y, mi buen teniente, creo que sabeis cuánto os estimo. (Shakespeare 2004 343).

70. Hay que destacar que un asesino es considerado "un artista profesional digno de respeto y, como tal, hay que tratarlo en la mesa" (Martín 1998: 11). Por tanto, hay un bagaje cultural en el que un asesino puede formar parte de un banquete.

71. Rey- ¡Gertrud! ¡No bebais!

Reina- perdonadme, señor, pero quiero beber.

Rey- [aparte] Es la copa envenenada. Demasiado tarde...

La reina cae. (Shakespeare 1996: 697-701).

72. Reina- ¡No, no, no!... La bebida... ¡Hamlet, hijo! La bebida, la bebida. ¡Me han envenenado! (Muere) (Shakespeare 1996: 703).

73. Laertes- Aquí está, Hamlet... Y tú, herido de muerte. No hay medicina en el mundo que pueda salvarte... Llevas en tu propia mano el instrumento traidor, ... que ya caigo... para nunca jamás alzarme del suelo... A vuestra madre también la envenenaron... Ya desfallezco... El rey... el rey es el culpable. (Shakespeare 1996: 705). 
Give me the cup; let go; by Heaven, I'll have it.-...

o, I die, Horatio ${ }^{74}$. (Shakespeare: 818; énfasis añadido)

Como destaca Mainardi y Berta (1991: 120), en esta tragedia "'Questo vino diventa strumento di morte, ma porta a galla anche tutta la veritá". El vino se convierte en un elemento negativo con el que conseguir objetivos egoístas y da paso a un mundo terrible. Un mundo lleno de mentiras, deslealtades, intereses oscuros y egoísmos, que acaba convirtiendo al vino en un instrumento de verdad al mostrar cómo se han conseguido todas esas deslealtades. Además, el vino se utiliza para acabar en muerte.

Se podría decir que es un contrapunto al mundo verde que aparece en las comedias de Shakespeare. Los bosques de las comedias, como en As You Like It, The Two Gentlemen of Verona or Love's Labour Lost es un locus amoenus donde se retorna a la simplicidad, a la verdad o a la lealtad (Nevo 1980: 184). En ocasiones también lo han definido como un lugar de libertad (Lerner: 1967: 228, Therle Lawrence 1969: 169 y Legatt 1978: 195) y donde los personajes son libres. $\mathrm{Si}$ en algún momento aparece el desorden, como en A Midsummer-Night's Dream, es de forma amable y como preludio de la concordia posterior. Como destaca Frye (1973: 182), "Shakespeare's type of romantic comedy... we may call it the drama of the green World, its plot being assimilated to the ritual of the triumph of life and love over the waste land".

A veces la negatividad del vino se utiliza para disfrazar los sentimientos y hacer creer que se siente algo distinto.

Falstaff- and the fire of grace be not quite

Out of thee, now shalt thou be moved. - give

Me a cup of sack, to make mine eyes look red,

That it may be thought I have wept, for I must

Speak in passion, and I will do it in King Cam-

Byses' vein. (Shakespeare 1993: 353; énfasis añadido) ${ }^{75}$

74. Hamlet- ¡Bebe hasta la última gota del veneno!... Únete a mi madre.

El rey muere.

Laertes- Muero por el veneno que él preparó...

Hamlet- El cielo ha de perdonarte... Yo te acompaño... Ya muero, Horacio.

Dame ese caliz. ¡Suéltalo! ipor el Cielo Santo!... Muero, Horacio. (Shakespeare 1996: 708-709).

75. Falstaff- Bueno; si el fuego de la gracia no está completamente extinguido en ti, te vas a impresionar al momento. Dame una copa de canarias para enrojecerme los ojos, a fin de que pueda creerse que he llorado, porque es menester que hable con pasión y voy a hacerlo al estilo del rey Cambyses. (Shakespeare $2000 \mathrm{~d}: 650)$. 
Armstrong y Atkin (1998: 122) comentan que en este ejemplo Falstaff ridiculiza la nobleza al querer imitar a un rey. Además, destacan el juego de públicos que tiene Falstaff en ese momento, tanto en el escenario como fuera del mismo. Por tanto, está exponiendo la ilusión del teatro y tiene un efecto cómico. Para ello ha utilizado el vino y demuestra uno de sus trucos para manipular y mostrar, así, su negatividad.

En otras ocasiones aparece el fantasma de un personaje asesinado, utilizando el vino. Así en Richard III, Clarence es llevado a prisión, donde dos asesinos lo ahogan en vino malvasía, como remarca Kott (1966: 34), más adelante el fantasma de Clarence denuncia tal situación, una vez sucedida.

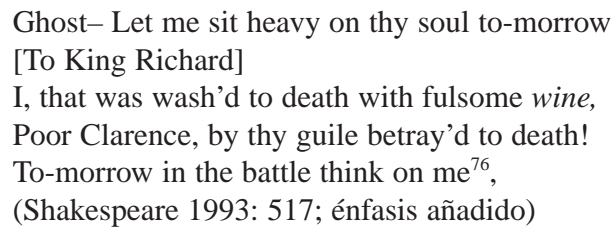

En este ejemplo vemos que el fantasma de Clarence denuncia la forma en la que fue asesinado; esto es ahogado en vino, una escena perteneciente al principio de la obra. De nuevo, el vino se une con la traición y la muerte.

En otras ocasiones el mal generado por el exceso de vino se ve perdonado, como sucede en la obra histórica de Henry V:

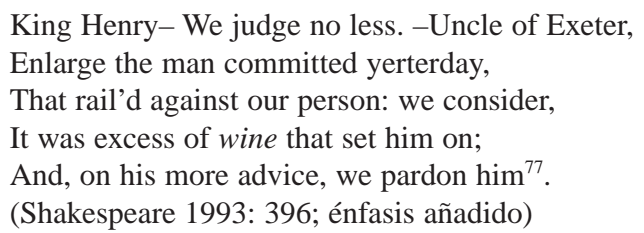

El rey comprende que no ha sido libre para cometer delito, ya que había bebido en exceso. El rey entiende que no era dueño de sí mismo y por eso le perdona. Por tanto, este perdón hace destacar el carácter de justicia del rey.

Existen otros dos ejemplos en The Tempest, donde se une el vino con la debilidad.

76. Espectro- [al rey Ricardo] ¡Mañana pesaré con fuerza abrumadora sobre tu alma! Yo, el que fue ahogado en un vino nauseabundo, pobre Clarence, por tu perfidia entregado a la muerte! ¡Médita en mí, durante el combate (Shakespeare 2000 d: 797).

77. Rey Enrique- No esperamos menos. Tío de Exeter: libertad al hombre que ayer fue metido en prisión por haberse mofado de mi persona. Hemos reflexionado que le impulsó a ese delito el exceso de vino y, con más detenido juicio, le perdonamos. (Shakespeare $2000 \mathrm{~d}$ : 847). 
Stephano- My man-monster hath drowned his tongue in sack: for my part, the sea cannot drown me: ${ }^{78}$

(Shakespeare 1993: 11; énfasis añadido)

Trinculo- I did not give the lie: Out o'your wits, and hearing too? -A pox o'your bottle! this can sack, and drinking do. A murray on your monster, and the devil take your fingers! $!^{79}$ (Shakespeare 1993: 11; énfasis añadido)

En el primer ejemplo Stephano disculpa a Caliban por haberse emborrachado. Él, que no lo hizo, pudo llegar bien a la orilla, después del hundimiento. En el segundo Trínculo reconoce la mala situación a la que se les ha conducido por beber en exceso vino. Por eso culpa a Caliban de su suerte, ya que le considera responsable de haber perdido la cabeza.

En otras ocasiones aparece la referencia del vino para justificar la borrachera del personaje. Así en The Tempest:

Alonso- Is not this Stephano, my drunken butler?

Sebastian- He is drunk now: where had he wine $?^{80}$

(Shakespeare 1993: 17; énfasis añadido)

En los siguientes ejemplos de Anthony and Cleopatra, vemos cómo se considera que el vino debilita el sentido del que lo bebe.

Mark Anthony-Come, let us all take hands;

till that the conquering wine hath steep'd our sense

in soft and delicate Lethe...

Octavius Caesar- You see we have burnt our cheeks: strong

Enorbarbe

Is weaker than the wine; and mine own tongue

Splits what it speaks: ${ }^{81}$ (Shakespeare 1993: 653; énfasis añadido)

78. Stephano- ¿Qué? ¿Se le ha ahogado la lengua a mi hombre-monstruo en el Jerez? A mí, ni todo el mar podría ahogarme. (Shakespeare 1994: 273).

79. Trínculo- Yo no te he dicho que mientes. ¿Has perdido los sesos y los oídos? ¡Maldita botella! A esto hemos llegado por el Jerez y por la bebida. Caiga sobre tu monstruo la peste roja y que el diablo se os lleve los dedos. (Shakespeare 1994: 283).

80. Alonso- ¿No es éste Stefano? ¿Nuestro borracho cantinero?

Sebastian- Está ebrio, efectivamente. ¿De dónde habrá sacado el vino? (Shakespeare 1994: 415).

81. Antonio- Vamos, démonos todos las manos, hasta que el vino invasor haya hundido nuestros sentidos en el blando y delicado Leteo. (Shakespeare 1983: 120).

César- ya veis que hemos incendiado nuestras mejillas. El fuerte Enobarbo es más débil que el vino, y mi propia lengua parte lo que dice. (Shakespeare 1983: 121). 


\section{Lo mismo sucede en el siguiente ejemplo de Timon of Athens.}

Apemantus- Ay; to see meat fill knaves, and wine heat fools ${ }^{82}$. (Shakespeare 1993: 575; énfasis añadido)

En esta cita el personaje expresamente denomina idiota al que se deja calentar por el vino; es decir, el que se deja engañar.

En el siguiente caso de Timon of Athens se señala el despilfarro que causa el vino cuando se llega a la borrachera, ya que el estar borracho supone un estado en el que uno no se puede controlar. Así,

Flavius- If you suspect my husbandry, or

falsehood,

call me before the exactest auditors,

and set on the proof. So the gods bless me,

when all you offices have been oppress'd

with riotous feeders; when our vaults have wept

with drunken spilth of wine; when, every room

hath blaz'd with lights, and bray'd with

minstrelsy:

I have retir'd me to a wasteful cock,

and set mine eyes at flow ${ }^{83}$. (Shakespeare 1993: 579; énfasis añadido)

Existe otro caso en The Comedy of Errors donde se une el vino con el perder la razón y la coherencia. Así,

Ofephesus- My liege, I am advised what I say;

Neither disturbed with the effect of wine,

Now heady rash, provok'd with raging ire,

Albeit, my wrongs might make one wiser mad,

This woman lock'd me out this day from dinner ${ }^{84}$.

(Shakespeare 1993: 278; énfasis añadido)

82. Apemanto- Sí; para ver la vianda ahogar a los granujas, y el vino calentar a los idiotas. (Shakespeare 2000 b: 530).

83. Flavio-Si sospechais de mí como despilfarrador o defraudador, hacedme citar ante los más rigurosos expertos y obligadme a rendir cuentas. ¡Los dioses me bendigan! Cuando todos nuestros aposentos estaban atestados de comensales escandalosos; cuando todas nuestras cuevas lloraban olas de vino derrochado en la borrachera; cuando cada sala se hallaba deslumbrante de luces y atronadora de cánticos, me he apoyado muy a menudo sobre uno de esos toneles prodigados y he dejado correr mis lágrimas. (Shakespeare 2000 b: 548).

84. Antífolo de Éfeso- Monseñor, hablo racionalmente; no turban mi razón los vapores del vino, ni la colera, aunque bastarían tales injurias para volver locos a otros más cuerdos que yo. Hoy, cuando he ido a comer, se ha negado esa mujer a recibirme. (Shakespeare 2000 c: 72). 
Mainardi y Berta (1991: 118) destacan que "Il vino di Otello, Macbeth, Amleto assume le tinte trapiche di questi famosi drammi" (Mainardi y Berta 1991: 118). Además se puede añadir que en los ejemplos que hemos estudiado el vino contribuye a la creación del problema y el climax de la obra pues sirve para matar al rey en Macbeth o crear los problemas del general en Merchant of Veni$c e$. Por tanto, en el resto del drama se tiene que solventar el problema creado.

\section{Conclusión}

Como se ha observado es alto el porcentaje de obras en las en las que se alude al vino en Shakespeare, lo que nos ha proporcionado cuantiosos ejemplos en este estudio. Éstos nos han permitido apreciar el valor significativo del vino en la estructura de las obras, al subrayar momentos climáticos, relajados o siendo imprescindible en el desarrollo de la intriga o en la causa que desenlaza el drama.
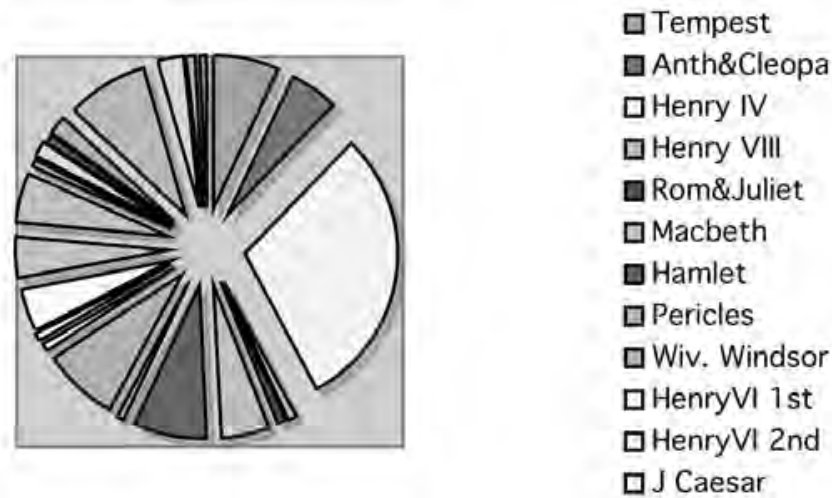

Como se aprecia visualmente en el diagrama que se adjunta destaca el porcentaje de referencias al vino en Henry IV especialmente, aunque también es importante su utilización en The Tempest, Anthony and Cleopatra, Macbeth, Hamlet, Merry Wives of Windsor, Othello, The Moor of Venice y en menor medida en The Life and Death of Julius Caesar y Twelfth Night. Finalmente, también se utiliza mínimamente en Henry VIII, Romeo and Juliet, Pericles, Prince of Tyre, las dos partes de Henry VI, Much Ado about Nothing, Taming The Shrew, King Lear, Merchant of Venice, Richard III, Henry V y The Comedy of Errors. Aunque también hay que tener presente que, a pesar de no utilizarse mucho el vino en algunos de estas últimas obras, puede tener una importancia vital. Por ejemplo en Taming The Shrew, donde su efecto cómico es destacable en una de las escenas. 
También resalta la variedad de temas con los que se puede relacionar el vino. Hemos estudiado los que más se reiteran en la obra teatral de Shakespeare. Puede haber otros temas marginales relacionados con su utilización, como la recompensa en Merry Wives of Windsor o para mostrar las diferencias entre los propios vinos y destacar el de la región del Rhin en Merchant of Venice. Sin embargo, hemos optado en este estudio por analizar los temas que mayoritariamente aparecen relacionados con el vino en la obra dramática de Sakespeare. Para ello se han rastreado todas los ejemplos donde aparece el vino en dicha obra.

El vino se muestra con su poder curativo en The Tempest y Anthony and Cleopatra, tanto para recuperar fuerzas como para curar heridas externas. Su utilización es realista y aparece en momentos de anticlímax, en los que los personajes retoman fuerzas, y ayuda a contextualizar las situaciones. El vino también se muestra como inspirador de fuerza y valentía en momentos previos a un climax importante, como sucede en Henry $V$ con una batalla. Por otro lado, el vino también se utiliza para olvidar momentos difíciles y, por tanto, son situaciones de anticlímax donde los personajes se relajan. Así se observa en Merchant of Venice, Henry IV, Richard III y The Life and Death of Julies Caesar. Son momentos en los que queda patente la debilidad de los personajes.

El vino aparece unido a la fiesta y banquetes en Henry IV, The Life and Death of King Henry the Eighth, Romeo and Juliet, Macbeth, Hamlet, Pericles y King Henry VI. Como en casos anteriores, el vino ayuda a contextualizar las situaciones. Dibuja momentos de tranquilidad y celebración, además de formar parte de una convención social: ofrecer vino junto con alimentos o, simplemente, ofrecer vino para celebrar la amistad o un evento. En este sentido, también hemos demostrado que el vino está vinculado a la clase alta y la cerveza, a la popular. Así aparece en Anthony and Cleopatra, The Life and Death of Julies Caesar, Twelfth Night, Timon of Athens, Much Ado about Nothing. Un interés especial ofrece Taming the Shrew en la broma que se gasta al criado Sly, haciéndosele pasar por señor y, por tanto, bebedor de vino, en vez de cerveza, como era su costumbre. Es un momento cómico y distendido, donde el vino y la copa de cristal son centrales para subrayar la comicidad y la diferencia de estatus social.

Esto demuestra el carácter de distinción que posee el vino frente a otras bebidas alcohólicas de la época. Así el vino se bebe en elegantes recipientes de vidrio entre los miembros de la clase alta y la cerveza se ofrece en toscos recipientes en las tabernas.

También destaca con entidad propia Fastaff en este estudio sobre vino. A pesar de pertenecer a la clase baja, al ser amigo del príncipe de Gales, conoce el vino, 
especialmente el de Canarias, y le gusta beberlo. Este personaje se ha estudiado con citas pertenecientes a Henry IV y Merry Wives of Windsor. Aparece como bravucón, juerguista y débil por su vinculación al vino. Sin embargo, también hay momentos en los que se destacan las características positivas del vino, ya que las une a la destreza de las armas y cuando sucede esto, lo asocia al príncipe Hal.

Finalmente, el vino, que había sido un brebaje curativo, es también una bebida nociva para el alma y el cuerpo, en el sentido de la palabra griega "farmakon" de Platón con el doble significado de remedio y veneno. De esta manera, en el sentido de brebaje nocivo el vino aparece unido a la traición y al engaño en momentos de gran tensión dramática. Normalmente forma parte del nudo de la trama. Así el asesinato de Duncan en Macbeth, la deshonra de Casio en Othello, el engaño femenino de Merchant of Venice o la ingesta de veneno en Hamlet no se podrían entender sin la figura del vino. Su uso como droga desleal permite a los personajes malévolos conseguir sus objetivos egoístas.

Además al analizar toda la obra dramática de Shakespeare, hemos estudiado el vocabulario que utiliza el autor para hablar del vino. Básicamente utiliza las palabras wine y sack. Ya en sack y especialmente en su definición se aprecia la relación del vino con España, sobre todo con las Islas Canarias. Sin embargo, Shakespeare también utiliza los términos sherris y canaries, lo que demuestra claramente su procedencia española.

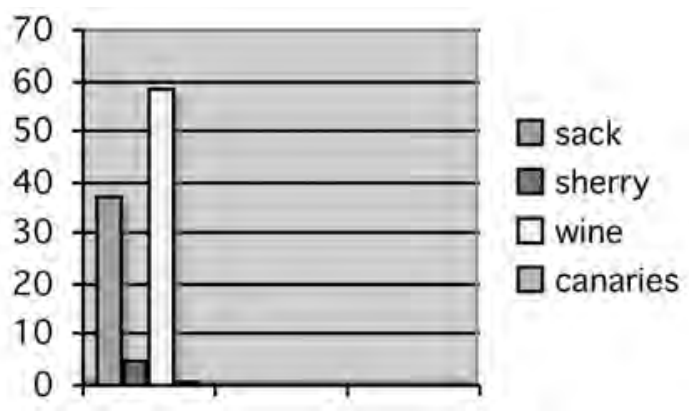

Como vemos en el gráfico, Shakespeare utiliza básicamente los términos de wine y sack. En menor medida hace uso de sherry y canaries. Sin embargo, merece la pena destacar la influencia de estos dos últimos términos hasta el punto de calar en la lengua inglesa y pasar a ser sustantivos, dejando atrás su carácter calificativo y su función de adjetivos. Hay un único ejemplo en el que Shakespeare hace referencia a otro vino, el de las tierras cercanas al río Rhin, y lo hace utili- 
zando un adjetivo. En Merchant of Venice el autor lo denomina Rhenish wine. La utilización de estos términos en el lenguaje demuestra la relevancia de los vinos españoles. Por otro lado, cabría señalar que los vinos del Rhin italianos sirven para contextualizar una trama que tiene lugar en Italia, Merchant of Venice. Sin embargo, la utilización de los términos sack, canaries y sherris por personajes ingleses en suelo británico señala su habitualidad en las prácticas sociales del momento.

En general, el vino en las obras dramáticas de Shakespeare da realismo, porque responde a un uso social. Puede ser objeto de chanzas y risas o formar parte indispensable de un crimen terrible. Su uso contextualiza la acción o subraya el nudo de la acción de la obra teatral.

\section{Bibliografía}

ARMSTRONG, C. y ATKIN, G. (1998). Studying Shakespeare. A Practical Guide. Londres: Prentice Hall Europe.

BÉTHENCOURT MASSIEU, A. (2003). Canarias e Inglaterra: El comercio de vinos (1650-1800). Santa Cruz de Tenerife: Ediciones Idea.

BUJANDA FERNÁNDEZ DE PIEROLA, L. 2001. Efectos del vino en la salud. Barcelona: Prous Science.

COHEN, W. (1983). "The Merchant of Venice and the Possibilities for Historical Criticism". English Literary History 49: 765-89.

DAICHES, D. (1979). A Critical History of English Literature. Shakespeare to Milton. London: Morrison \& Gibb.

FERNÁNDEZ MARTÍN-GRANIZO, I. (1999). El vino y la salud. Aprendemos a beber. León: Everest.

FIGELMAN, F. (1985). The American Heritage Dictionary. Boston: Houghton Mifflin.

FRYE, N. (1973). Anatomy of Criticism. Four Essays. Yale: Yale University Press. FRYE, N. (1986). Northrop Frye on Shakespeare. New York: Vail-Ballou Press. GARCÍA MÁRQUEZ, J. y GARCÍA MAIQUEZ, E. (2001). "El vino entre la alimentación y la salud en el mundo antiguo (Grecia y Roma)". En PÉREZ RODRÍGUEZ, L; GÓMEZ BENÍTEZ, J. y PALACIOS MACIAS, V.M. (Eds.) (2001). El vino y la alimentación y la salud. IV encuentros de primavera de la Universidad de Cádiz en el Puerto de Santa María. Cádiz: Universidad de Cádiz; El Puerto de Santa María: Ayuntamiento: 147-154.

HYLAND, P. (1996). An Introduction to Shakespeare. The Dramatist in his Context. Londres: Macmillan Press. 
KERMODE, F. (2001). Shakespeare's Language. Londres: Penguin Books.

KERMODE, F. 2005. El tiempo de Shakespeare. New York: Random House Mondadori.

KINNEY, A. F. (2001). Lies Like Truth. Shakespeare, Macbeth and the Cultural Moment. Detroit, Michigan: Wayne State University Press.

KOTT, J. (1966). Shakespeare our Contemporary. New Cork: WW Norton.

LEGATT, A. (1978). Shakespeare' Comedy of Love. Londres: Methuen.

LERNER, L. (1967). Shakespearer's Comedies. Londres: Penguin.

LORENZO-CÁCERES, A. (1941). Malvasia y Falstaff. Los vinos de Canarias. La Laguna: Instituto de Estudios Canarios.

LUCERO et al. (Ed.) (1990). Actas Simposio Internacional. El vino en la literatura española medieval presencia y simbolismo. Mendoza (Argentina): Universidad Nacional de Cuyo, Facultad de Filosofía y Letras.

MACLEISH, K. y UNWIN, S. (2000). Guía de las obras dramáticas de Shakespeare. Barcelona: Alba editorial.

MAINARDI, G. Y BERTA, P. (1991). Il vino nella storia e nella letteratura. Milán: Edizioni Agricole.

MALEY, W. (2003). Nation, State and Empire in English Renaissance Literatura. Shakespeare to Milton. New York: Palgrave Macmillan.

MARTÍN, J.L. (1998). El vino y la buena mesa medieval. Logroño: Universidad Nacional de Educación a Distancia, Centro Asociado de La Rioja.

MORAGÓN ARIAS, M.P. (1994). "Los distintos envases de vidrio utilizados para el vino a través de la historia: Edad Antigua y Media". En Jornadas de Viticultura y Enología de Tierra de Barros (15. 1993. Almendralejo). Mérida: Junta de Extremadura: 525-536.

MURO MUNILLA, M.A. (2006). El cáliz de letras: historia del vino en la literatura. Briones, La Rioja: Fundación Dinastía Vivanco.

NEVO, R. (1980). Comic Transformations in Shakespeare. Londres: Methuen.

OROZ RETA, J. (1985). "El vino y los banquetes en la literatura griega". En Jornadas de Viticultura y Enología de Tierra de Barros (7. 1985. Almendralejo). Almendralejo: Universidad de Extremadura: 37-38.

OTERO ALVARADO, M.T. y VERDUGO SANTOS, J. (1996). "Vino, banquete y comunicación social en la antigüedad". En Jornadas de Viticultura y Enología de Tierra de Barros (17. 1996. Almendralejo). [S.1.]: Junta de Extremadura: 341-352.

PAN SÁNCHEZ, M.R. (1994). "Navarra y la literatura inglesa II: La presencia de Navarra en algunas obras de William Shakespeare y en la comedia anónima The Tryall of Chevalry". Notas y estudios filológicos, 9: 151-170. 
PÉREZ CASAUX, M. (1986). "El jerez en la obra de Shakespeare". En García Pazos (coord.) Jornadas del vino fino (7. 2001. El Puerto de Santamaría). El Puerto de Santa María, Cádiz: Ayuntamiento: 25-36.

PÉREZ GÁLLEGO, C. (1989). "Una reina y dos príncipes: Aragón en la obra de Shakespeare". Boletín de Museo e Instituto Camón Aznar 36: 23-38.

PÉREZ RODRÍGUEZ, L; GÓMEZ BENÍTEZ, J. y PALACIOS MACIAS, V.M. (Eds.) (2001). El vino y la alimentación y la salud. IV encuentros de primavera de la Universidad de Cádiz en el Puerto de Santa María. Cádiz: Universidad de Cádiz; El Puerto de Santa María: Ayuntamiento.

SHAKESPEARE, W. (1946). A buen fin no hay mal principio y Trabajos de amor perdidos. Buenos Aires: Austral.

SHAKESPEARE, W. (1948). A vuestro gusto. Buenos Aires: Austral.

SHAKESPEARE, W. (1981). Romeo y Julieta y Julio César. Barcelona: Planeta.

SHAKESPEARE, W. (1983). Tito Andrónico, Antonio y Cleopatra, Coriolano y Cimbelino. Barcelona: Planeta.

SHAKESPEARE, W. (1985). As You Like It. Londres: Methuen.

SHAKESPEARE, W. (1993). The complete Works of William Shakespeare with the Life of the Poet. London: Ramboro Books.

SHAKESPEARE, W. (1994). La tempestad. Madrid: Cátedra.

SHAKESPEARE, W. (1995). El rey Lear. Madrid: Cátedra.

SHAKESPEARE, W. (1996). Hamlet. Madrid: Cátedra.

SHAKESPEARE, W. (1997). Noche de Reyes. Madrid: Cátedra.

SHAKESPEARE, W. (2000a). Comedias oscuras. William Shakespeare. Madrid: Espasa.

SHAKESPEARE, W. (2000b). Dramas clásicos. William Shakespeare. Madrid: Espasa.

SHAKESPEARE, W. (2000c). Grandes comedias William Shakespeare. Madrid: Espasa.

SHAKESPEARE, W. (2000d). Dramas históricos William Shakespeare. Madrid: Espasa.

SHAKESPEARE, W. (2004). Obras selectas. Madrid: Edimat Libros.

THERLE, W.W. (1969). Shakespeare's Problem Comedies. Londres: Penguin.

WILSON, S. (1995). Cultural Materialism. Theory and Practice. Oxford: Blackwell. 